\title{
NAVY DEPARTMENT
}

THE DAVID W. TAYLOR MODEL BASIN

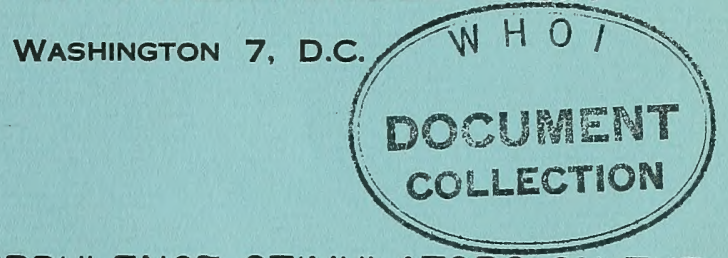

EFFECTS OF TURBULENCE STIMULATORS ON THE BOUNDARY LAYER AND RESISTANCE OF A SHIP MODEL AS DETECTED BY HOT WIRES

\section{by}

John P. Breslin and Morris S. Macovsky

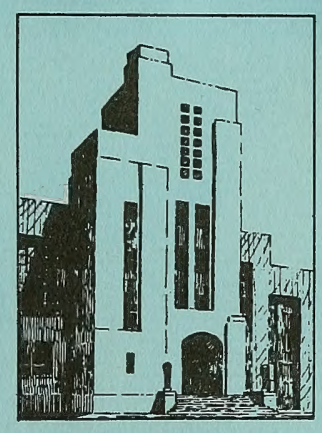

August 1950

Report 724

NS $715-0.86$

.03

no. 724 


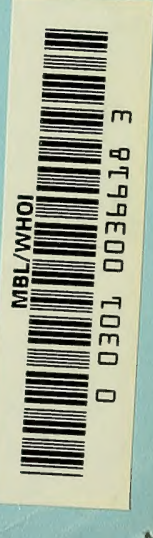




\section{INITIAL DISTRIBUTION}

Copies

10 Chief, BuShips, Project Records (Code 362) for distribution:

3 Project Records

2 Physics (Code 332)

3 Research (Code 330)

1 Propellers and Shafting (Code 654)

1 Technical Assistant to Chief of the Bureau (Code 106)

4 Chief, BuOrd, Underwater Ordnance (Re6a)

3. Chief, BuAer, Aerodynamics and Hydrodynamics (DE-3)

6 Chief of Naval Research, Fluid Mechanics (Code N426)

2 Director, Naval Research Laboratory, Washington 20, D.C.

3 Commander, Naval Ordnance Laboratory, Mechanics Division, White Oak, Silver Spring, Md.

3 Commandex, Naval Ordnance Test Station, (UOD), Pasadena, Calif.

1 Commanding Officer and Director, U.S. Navy Underwater Sound Laboratory, New London, Conn.

5 Director of Aeronautical Research, National Advisory Committee for Aeronautics, $1724 \mathrm{~F}$ St, N.Wo, Washington 25, D.C。

1 Director, U.S.Waterways Experiment Station, Vicksburg, Miss.

1 Director, Woods Hole Oceanographic Institution, Woods Hole, Mass.

2 Supervisor, Hydraulic Laboratory, Newport News Shipbuilding and Dry Dock Co., Newport News, Va。

2 Director, Technical Information Division, Aberdeen Proving Ground, Aberdeen, Md.

1 Prof.W.S. Hamilton, Technological Institute, Northwestern University, Evanston, III。

1 Prof. K.E. Schoenherr, School of Engineering, Notre Dame University, South Bend, Ind.

2 British Ministry of Supply, Washington, D。C。

2 British Joint Services Mission (Navy Staff), Washington, D.C.

2 Australian Scientific Research Liaison office, Washington, D.C.

2 Director, Hydrodynamics Laboratory, National Research Council, Ottawa, Canada

2 Director, Oranance Research Laboratory, Pennsylvania State College, State College, $\mathrm{Pa}$. 

4 Director, Experimental Towing Tank, Stevens Institute of Technology, Hoboken, N.J.

2 Director, Iowa Institute for Hydraulic Research, University of Iowa, Iowa City, Iowa

2 Director, Hydrodynamics Laboratory, California Institute of Technology, Pasadena, Calif。

2 Director, St. Anthony Falls Hydraulic Laboratory, University of Minnesota, Minneapolis 14, Mins。

2 Head, Department of Civil and Sanitary Engineering, Massachusetts Institute of Technology, Cambridge, Mass.

2 Director, University of Michigan Towing Tank, University of Michigan, Ann Arbor, Alich.

2 Dr. V.L. Streeter, Illinois Institute of Technology, 3300 Federal Street, Chicago 16, III.

2 Prof. T。Curran, Webb Institute of Naval Architecture, GIen Cove, Long Island, N。Y。

1 Dr。A. Schneider, U.S. Naval Ordnance Test Station, Pasadena Annex, Pasadena, Calif。

1 Director, Engineering Erperiment Station, University of Tennessee, Knoxville, Tenn. Atta: Dr。G.H. Hickox

1 Mr.W.C.Brenner, Westinghouse Atomic Power Division, Bettis Field, Pittsburgh 3, $\mathrm{Pa}$ 。

1 Dr.J.V。Wehausen, Editor, Mathematical Review, Providence, R.I.

2 Librarian, Society of Naval Architects and Marine Engineers,

29 W. 39 th Street, New York, N.Y.

2 Capt. F.X. Forest, USN, Portsmouth Naval Shipyard, Portsmouth, N.H.

1 Dr. Alexander Weinstein, Institute of Fluid Dynamics and Applied Mathematics, University of Maryland, College Park, Md.

1 Prof.W. Spannhake, Armour Research Foundation, 35 W. 33rd St。, Chicago 16, Ill.

2 Head, Dept。 of Naval Architecture and Marine Engineering, Massachusetts Institute of Technology, Cambridge 39, Mass.

1 Dr. G.B. Schubauer, National Bureau of Standards, Washington, D.C.

1 Prof.W.S. Owen, Webb Institute of Naval Architecture, GIen Cove, Long Island, N.Y. 

Copies

1 Librarian, American Society of Mechanical Engineers, 29 West Thirty - Ninth St。, New York $18, N . Y$.

1 Librarian, American Society of Civil Engineers, 33 West ThirtyNinth St, New York 18, N。Y.

1 Prof。J.K. Vennard, Departinent of Civil Engineering, Stanford University, Palo Alto, Calif。

I Prof.C.C。 Lin, Massachusetts Institute of Technology, Cambridge 39, Mass.

1 Dr. A. Donald Hay, School of Engineering, Princeton University, Princeton, N.J.

I Mr。A.I。Ponomaref, Westinghouse Electric Corporation, South Philadelphia, Pa。

1 Prof。W.C. Huntington, Head, Hydraulic Engineering Department, University of Illinols, Urbana, IIl.

2 Office, Chief of Engineers, (Mr。John C.Harrold), Engineering Division - Civil Works, Department of the Army, Washington 25, D。C 。 

ABSTRACT . . . . . . . . . . . . . . . . . . . 1

INTRODUCTION . . . . . . . . . . . . . . . . . . . . . . . . 1

BOUNDARY LAYER SURVEY OF MODEL OF AN OIL TANKER . . ....... . . 3

Description of Model . . . . . . . . . . . . . 3

Description of Apparatus and Test Methods . . . . . . . . . 3

Test Conditions . . . . . . . . . . . . . . . 10

ANALYSIS OF RESULTS OF BOUNDARY-LAYER SURVEY . . . . . . . . . . . 13

Theoret1cal Background . . . . . . . . . . . . . 13

Stability Theory of Laminar Flow . . . . . . . . . . . . 13

Qualitative Analysis ................ . . 16

Condition 1 - No Stimulation . . . . . . . . . . 16

Condition 2 - Stimulation by Rods . . . . . . . . . . 20

Condition 3 - Stimulation by $\operatorname{Tr} 1$ p Wire . . . . . . . . 20

Condition 4 - Stimulation by Sand Strip . . . . . . . . 22

Comparison of Effectiveness of Various Stimulators . . . . . . 22

Quantitative Analysis of Hot-Wire Data . . . . . . . . . 23

QUANTITATIVE ANALYSIS OF RESISTANCE TEST DATA . . . . . . . . 30

With and Without Stimulation ........... 30

Correction for Drag of a Trip Wire . . . . . . . . . . 32

Correction for Sand Strip Drag . . . . . . . . . . 33

Correction for Turbulence Rod . . . . . . . . . . . . 34

CONCLUSIONS . . . . . . . . . . . . . . . . . . 35

APPENDIX . . . . . . . . . . . . . . . . . 36

Theory of the Hot-Wire Technique as Applied to the Flow of Water . 36

Calibration and Sensitivity ............. 37

Frequency Response . . . . . . . . . . . . . . . 38

REFERENCES . . . . . . . . . . . . . . . . . . 39 



\title{
EFFECTS OF TURBULENCE STIMULATORS ON THE BOUNDARY LAYER AND
}

\section{RESISTANCE OF A SHIP MODEL AS DETECTED BY HOT WIRES}

\author{
by
}

John P. Breslin and Morris S. Macovsky

\begin{abstract}
An experimental study has been made of the effects of various methods of stimulating transition from laminar to turbulent flow in the boundary layer of a 25-foot tanker model. A hot-wire velocity instrument has been applied to determine the nature of the flow in the boundary layer. Qualitative and quantitative analyses of the results of the hot-wire surveys with a $1 / 8$-inch rod, a 0.032 -inch trip wire and a $7 / 8$-inch finegrain sand-strip used separately as stimulators are given. The theory of the stability of laminar flow which is briefly reviewed is used for qualitative interpretation of the boundary-layer flow found for the various test conditions. Expected increases in model resistance, because of stimulation as computed from hot-wire data, show good agreement with actual measured increases detected on the towing dynamometer when reasonable corrections are applied to the resistance data. The results of this study show that the hot-wire method is well suited to boundary-layer investigations in water, that the extent of laminar flow on the 25-foot model gives rise to a serious error in model resistance, and that measurable differences in the effects of various stimulators on the boundarylayer flow and on the model resistance can be determined. No conclusive decision can be reached as to the best stimulator, however, as a result of this study.

Details of the hot-wire theory as applied to measurements in water are given in the appendix.
\end{abstract}

\section{INTRODUCTION}

A frictional-resistance research program has been initiated at the David Taylor Model Basin ${ }^{2}$ to secure a thorough understanding of the frictional resistance of ship models. To this end, a program of fundamental research was set up and the development of special equipment undertaken. This program provides for the study of boundary-layer phenomena, first under simple conditions on flat plates and later on more complicated forms. During the period in

\footnotetext{
${ }^{1}$ References are listed on page 39 of this report.
} 
which the required equipment was being built it was decided to develop a qualitative technique for outlining the regions of laminar, transitional, and turbulent fiow on a ship model.

It is well known that laminar flow gives rise to smaller shearing stresses than turbulent flow at the same Reynolds number, and hence, that a resistance test of a model with a laminar layer over a portion of the wetted surface gives drag measurements from which the power predictions for the prototype may be seriously underestimated. It is also well known from windtunnel investigations and from theoretical studies on bodies of aerodynamic interest that the extent of the laminar region depends strongly upon the pressure distribution and hence the shape of the forebody. Consequently, misleading results might possibly be obtained from drag tests of several models representing, say, competitive bow lines for a ship or a geometric series of lines of varying forebody fullness because of the unequal laminar effects on each model.

Ship-model experimenters have long realized that such conditions prevall for small models and employ various devices to stimulate the boundary layer to secure a turbulent layer over the entire model. Evaluation of the effectiveness of the stimulators is made only by interpretation of the character of the resistance curve. Few attempts have hitherto been made to investigate the boundary-layer flow itself to ascertain the effectiveness of the stimulator in producing turbulent flow over the entire wetted surface. Large ship models (16 to $30 \mathrm{ft}$ ) have been used for years at the larger model basins to avold the difficulties of laminar flow encountered with small models. Those experimenting with large models have belleved that the model size and hence the Reynolds numbers were great enough to make negligible the effects of any possible laminar flow. However, recent studies have revealed that fullform models, even as long as $25 \mathrm{ft}$, have considerable laminar flow and that the resulting error may range from 2 to 10 percent of the power required by the ship even at designed speed.

The immediate problem of this project was to devise some method of detecting the extent of the laminar, transitional and turbulent flow over the surface of the model. Having accomplished this it would then be possible to assess the value of various devices which may be used to induce artificlally a turbulent boundary layer over the entire model. Several schemes were proposed including chemical and photographic techniques but the hot-wire method seemed to hold the most promise and has accordingly been pursued. This method, which will be described, has been used to survey the boundary-layer flow on a tanker model under varlous conditions of turbulence stimulation. The results 
of these surveys are compared with the results of drag measurements of the model under the same conditions or boundary-layer stimulation.

\section{BOUNDARY LAYER SURVEY OF MODEL OF AN OIL TANKER}

DESCRIPTION OF MODEL

In order to investigate the extent of the laminar boundary-layer region, a model of a full-form ship was selected for survey. A 25-foot model of a 600-foot tanker was selected because drag measurements on this model had given strong indications of the existence of laminar flow over a considerable portion of the wetted surface. It may be seen in Figure 1 that the vessel has full lines, the longltudinal prismatic coefficlent being 0.753 . The design Froude number, $\frac{U}{\sqrt{g L}}$, 1 s 0.208 - which gives a ship speed of 17.3 knots - where $U$ is the ship speed, $L$ is the length and $g$ is the gravitational acceleration. The linear ratio of ship to model is 24 , whence; following Froude's law of comparison, the corresponding model speed is 3.53 knots.

\section{DESCRIPTION OF APPARATUS AND TEST METHODS}

The constant-current hot-wire technique has been applied in this investigation to determine qualitatively the nature of the boundary-layer flow over the tanker model. The theory of the hot wire is briefly reviewed in the appendix of this report.

As shown in the appendix a wire placed in a flow and heated by a "constant" current produces a voltage drop which is a function of the squareroot of the velocity. Hence, velocity fluctuations of turbulence will be reflected as voltage fluctuations in the circuit. A thorough treatment of the theory and application of the hot wire in air has been written by Schubauer and Klebanoff? 2

The particular electrical circuit adapted to this investigation is illustrated in Figure $2 a$. Hot wires mounted on probes of the type shown in the photograph in Figure 2b, were separately connected to 4 circuits of this type. Each wire was heated by a current of 0.18 amp drawn from a 12-volt heavy-duty storage battery. This current, which was kept substantially constant, was sufficient to give a wire temperature $60^{\circ} \mathrm{F}$ greater than the ambient water temperature, which over the period of testing varied between $72^{\circ}$ and $74^{\circ} \mathrm{F}$. As shown in the sketch of the circult the voltage drop across the wire was fed into a TMB Type-3A current amplifier, the output of which was used to drive 4-mililampere galvanometers in a Consolidated oscillograph. Galvanometer responses were recorded photographically. The responses of as 

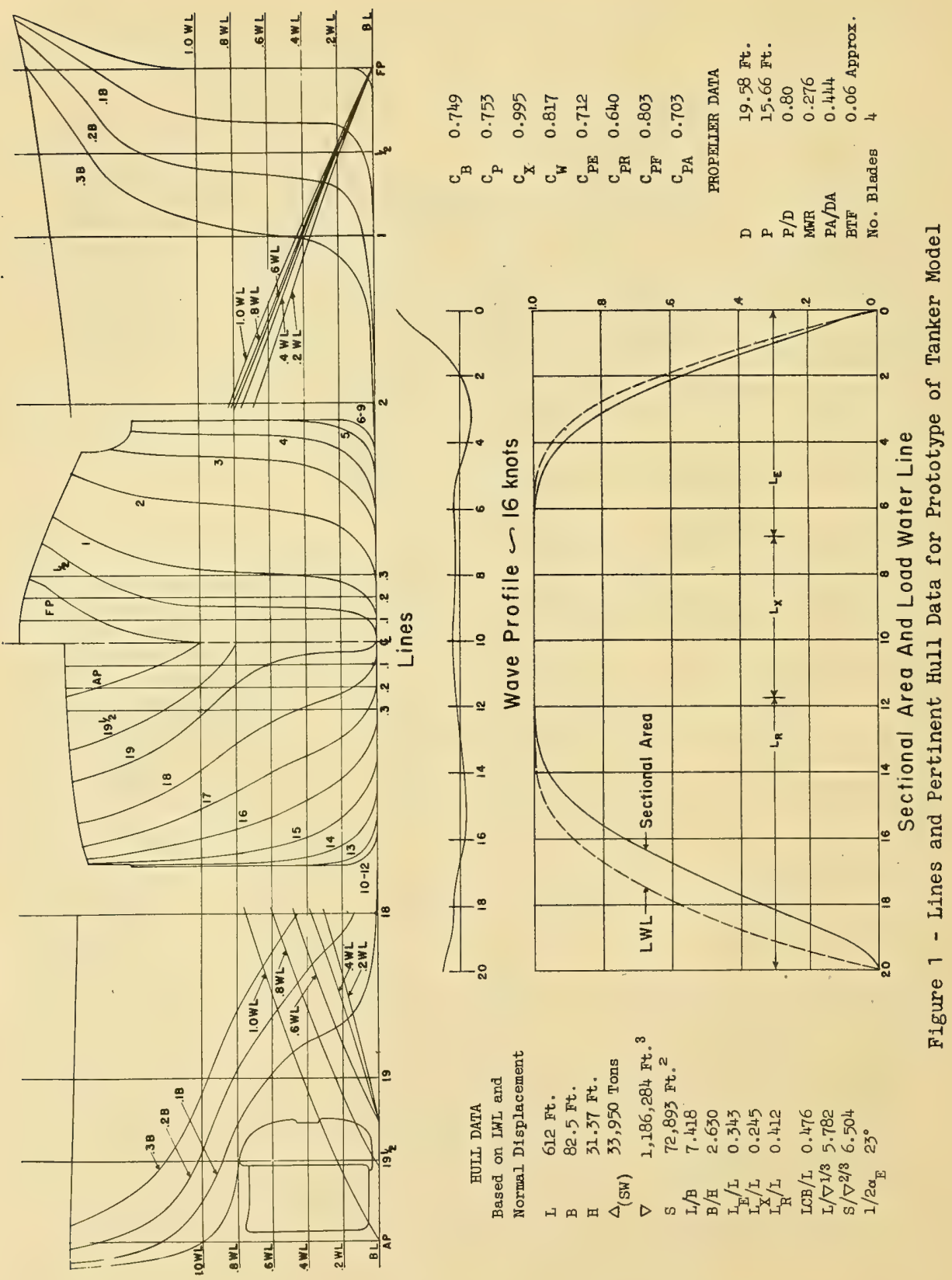

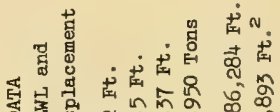

Noño:

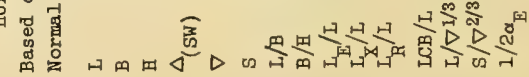




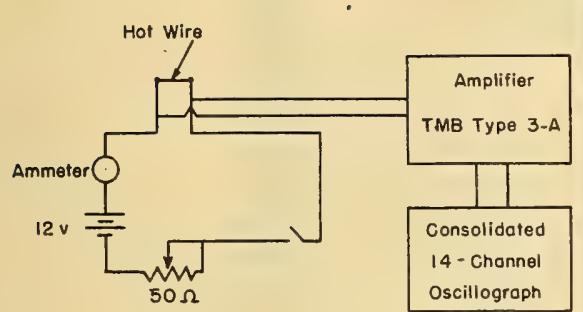

Figure 2a - Circult Used for Boundary-Layer Survey

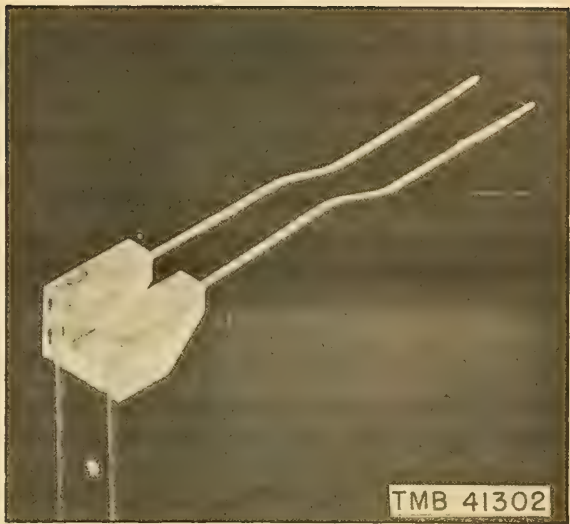

Figure $2 b$ - Hot Wire Probe Showing Plastic Handling Piece

Figure 2

many as 14 hot wires may be recorded simultaneously by this oscillograph but in this test only 4 channels at most were used at one time.

For this qualitative application of hot wires, neither calibration nor compensation for thermal-lag of the wires was attempted. In spite of this, a given wire reproduced relatively the same oscillogram for the same conditions, and repeated runs reproduced the same over-all boundary-layer "pictures" even after many hours of testing with the same wires. The problems of calibration and of compensation for thermal lag, as they arise in applying this technique to water measurements, are described in the appendix of this report.

For maximum sensitivity a wire must be placed perpendicular to the mean velocity of the flow. To find this direction at each of the 36 positions at which hot wires were to be installed, a single tube was inserted at each location and a lines-of-flow test was run at a mean speed of 1.75 knots. Figure 3 shows photographs of the result. The direction of the flow having been determined at each location, a line through the center of the tube was drawn perpendicular to the direction of flow. The second tube or socket for mounting the probe was located along this line, see Figure 4. A sketch showing how the wire is located with respect to the surface and a computed boundary-layer thickness is given in Figure 5. (The boundary-layer thickness is calculated from Equation [20], page 32.) The general arrangement of the probes may be seen in the photograph of Figure 6 . The location of the hot wires and the angles of the mean flow at each wire are given in Table 1 . 


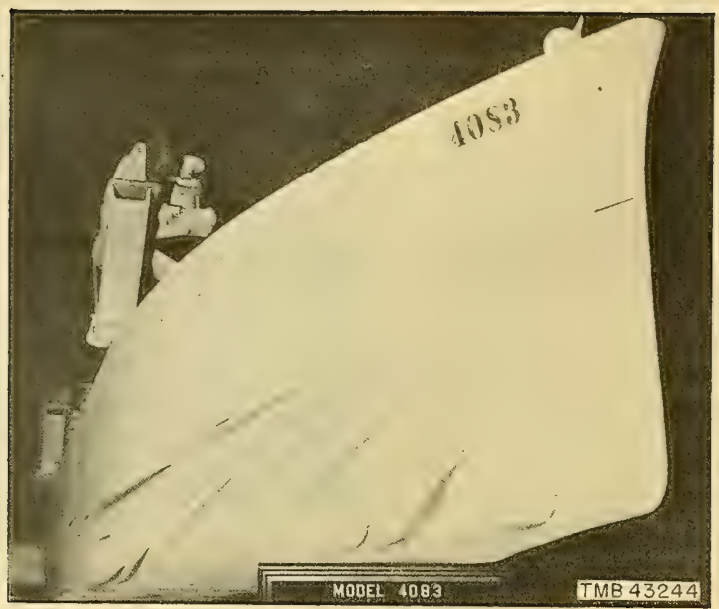

Figure $3 a$ - View of Starboard Side at Bow which Shows Flow Lines Passing Over the Bilge

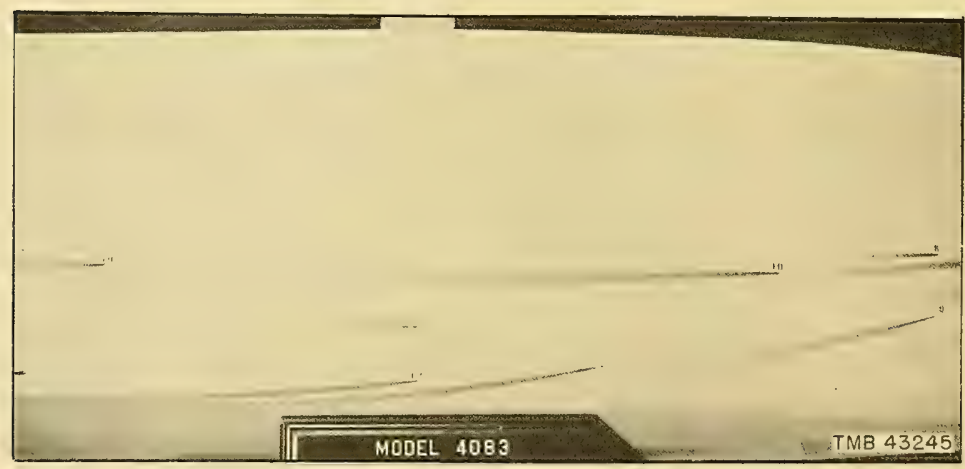

F1gure 3b - View of Starboard Side Forward of Amidships

Figure 3 - Flow Lines Determined by Hydrogen Sulphide-White Lead Technique for Orlentation of Hot-Wire Probes

The model was first towed with all probes in place but only the outputs of the wires in the first column were recorded, since the flow over the wires aft of these was found to be affected by the turbulent wake of the forward probes. After running through the complete schedule of speeds, the leading 3 wires were removed, the wires in the next column were connected to the recording circuit, and the schedule of conditions repeated. This process was continued until a station was reached where all the wires showed turbulent flow at the lowest speed of interest, 0.5 knot. 


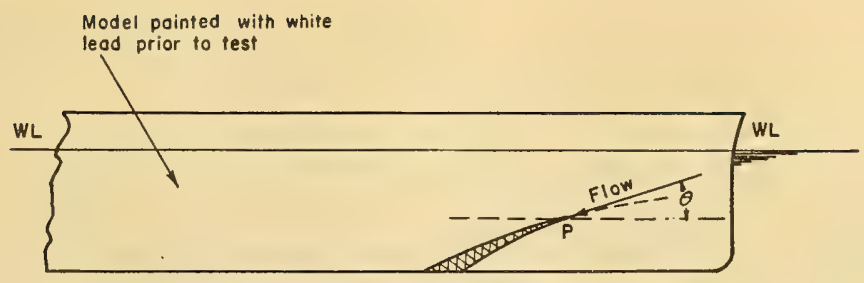

Bow of Tanker with Typical Flow Trace from Lines of Flow Test

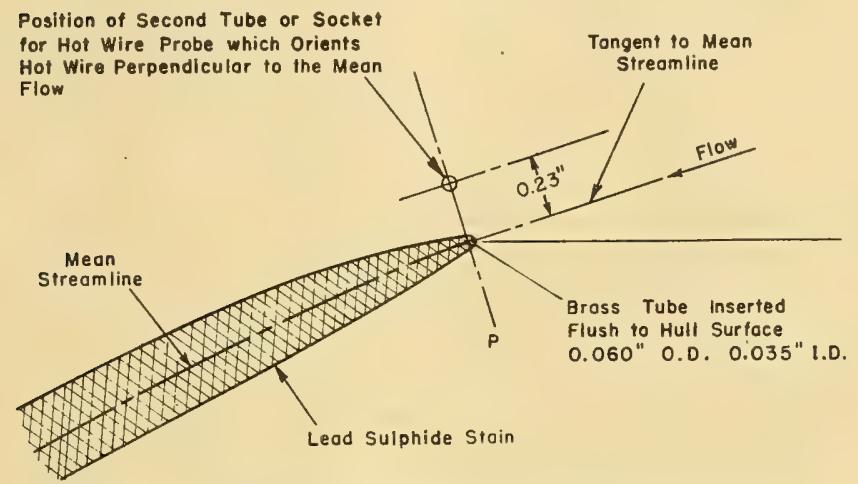

Enlargement of Hull Surface at Point where Hydrogen Sulphide is Ejected at a Fixed Towing Speed

Figure 4 - Technique Used for Orientation of Hot Wire at Selected Positions on Tanker Model

Classification of the flow at a probe is accomplished by interpreting the signal obtained from the probe. Typical "signatures" of laminar, transitional, and turbulent flow are shown in Figure 7. It may be seen that transition extends over a range of speeds, or more properly, of Reynolds numbers. These are based on a length measured from the bow along the half-draft water line to the start of the transition region. Furthermore, the occurrence of the turbulent bursts within the transitional range steadily increases until the flow becomes completely turbulent. There is another flow condition which for brevity has been omitted in Figure 7 and is represented in detail in Figure 8. This flow is laminar with low-frequency oscillations and is similar to the "laminar oscillations" observed in the boundary layer of a flat plate by Schubauer and Skramstad ${ }^{3}$ except that the oscillations in Figure 8 are much more randon than those reported in the earlier investigation. These laminar oscillations grow in magnitude and increase in frequency with increase in speed at a given poini in the boundary layer until turbulent bursts occur. 


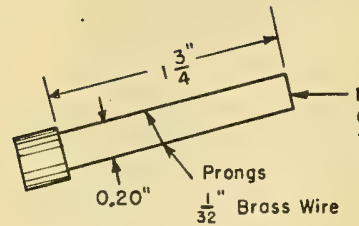

Side Elevation

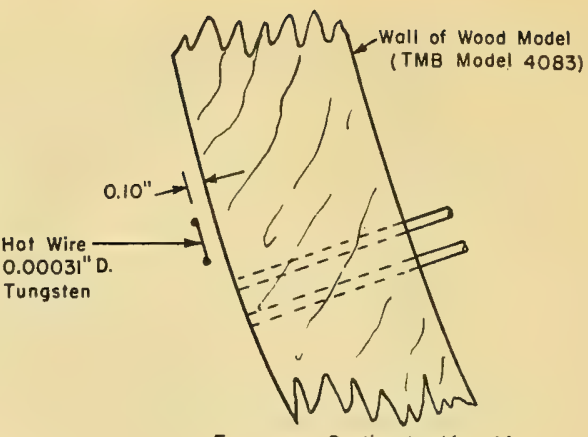

Transverse Section Looking Aft

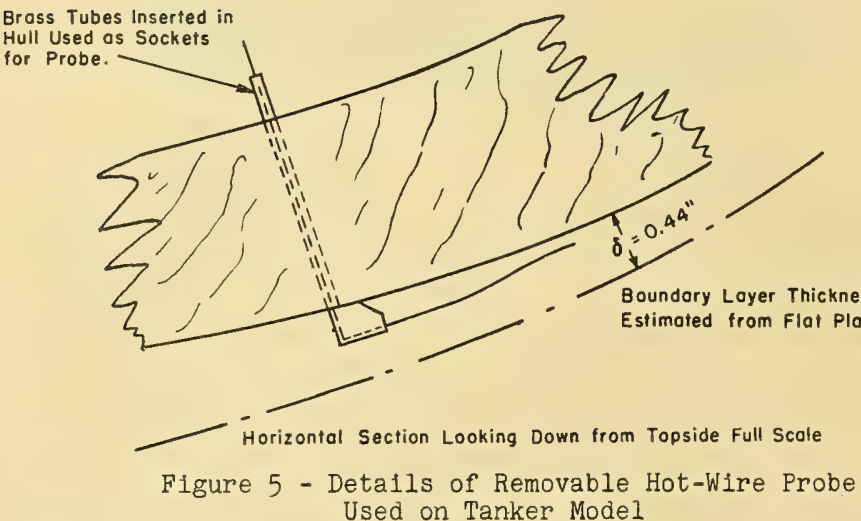

Thickness of laminar boundary layer computed from Equation [20] on page 32 for a position 3 ft from bow at a speed of 1.0 knot.

The first occurrence of turbulent bursts as shown in Figure 8 is taken as the onset of transition. In some instances it is difficult to distinguish between large laminar oscillations and low-frequency turbulence.* This uncertainty might be resolved by making a pitot-tube survey to determine if the mean velocity profile is laminar or turbulent. Although no pitot-tube surveys were conducted on this tanker model, plans are underway to substantiate the hotwire response to boundary-layer flow on a flat plate by simultaneous measurement of the boundary profile with total-head tubes. In any event, it is

*Records of this type were not common and were obtained at low speeds from wires placed far back on the hull. 
TABLE 1

Offsets and Orientation of Hot-Wire Probes on Tanker Model

The model length is 25.5 feet and draft is 15.7 inches

\begin{tabular}{|c|c|c|c|c|c|c|c|}
\hline $\begin{array}{l}\text { Probe } \\
\text { Number }\end{array}$ & $\begin{array}{c}x \\
\text { Inches }\end{array}$ & $\begin{array}{c}\mathrm{y} \\
\text { Inches }\end{array}$ & $\begin{array}{c}\theta \\
\text { degrees }\end{array}$ & $\begin{array}{l}\text { Probe } \\
\text { Number }\end{array}$ & $\begin{array}{c}x \\
\text { Inches }\end{array}$ & $\begin{array}{c}\mathrm{y} \\
\text { inches }\end{array}$ & $\begin{array}{c}\theta \\
\text { degrees }\end{array}$ \\
\hline 1 & 5.62 & 12.0 & 6 & 19 & 62.40 & 13.0 & 0 \\
\hline 2 & 5.00 & 7.0 & 28 & 20 & 62.25 & 8.0 & 3 \\
\hline 3 & 5.62 & 1.0 & 37 & 21 & 61.37 & 2.0 & 15 \\
\hline 4 & 11.87 & 10.0 & 11 & 22 & 74.25 & 13.0 & 0 \\
\hline 5 & 11.93 & 4.0 & 28 & 23. & 74.12 & 8.0 & 0 \\
\hline 6 & 18.50 & 13.0 & 8 & 24 & 73.18 & 1.0 & 10 \\
\hline 7 & 18.37 & 7.0 & 22 & 25 & 94.00 & 13.0 & 0 \\
\hline 8 & 18.30 & 1.0 & 33 & 26 & 93.87 & 8.0 & 0 \\
\hline 9 & 24.87 & 11.0 & 9 & 27 & 93.00 & 1.0 & 0 \\
\hline 10 & 24.75 & 6.0 & 22 & 28 & 122.37 & 14.0 & 0 \\
\hline 11 & 24.12 & 1.0 & 33 & 29 & 122.25 & 10.0 & 0 \\
\hline 12 & 37.75 & $13 . c$ & 4 & 30 & 121.37 & 1.5 & 0 \\
\hline 13 & 37.50 & 10.0 & 6 & 31 & 157.75 & 13.0 & 0 \\
\hline 14 & 37.30 & 6.0 & 17 & 32 & 157.62 & 6.0 & 0 \\
\hline 15 & 36.30 & 1.0 & 30 & 33 & 156.75 & 2.0 & 0 \\
\hline 16 & 50.00 & 13.0 & 2 & 34 & 182.25 & 13.0 & 0 \\
\hline 17 & 49.87 & 8.0 & 5 & 35 & 182.12 & 4.0 & 1 \\
\hline 18 & 48.25 & 1.0 & 20 & 36 & 34.30 & 0.0 & 0 \\
\hline \multicolumn{8}{|c|}{$\begin{array}{l}x \text { is the arc-length along a water line from the stem of the model to the hot-wire end of probe. } \\
y \text { is the height of the hot wire above the base line. }\end{array}$} \\
\hline
\end{tabular}

expected that the determination of the extent of the laminar region by means of the hot-wire response alone is sufficiently accurate for the present qual1tative study of the effects of various stimulators on the boundary-layer flow.

To insure that the fluctuations recorded from the hot-wire circuit were not originating from vibration of the probe or the wire itself two checks were made. A separate wire was mounted on a strut and towed about $18 \mathrm{ft}$ to one side of the model. For the same signal amplification no response was obtained from this wire while at the same time wires in the boundary layer of 


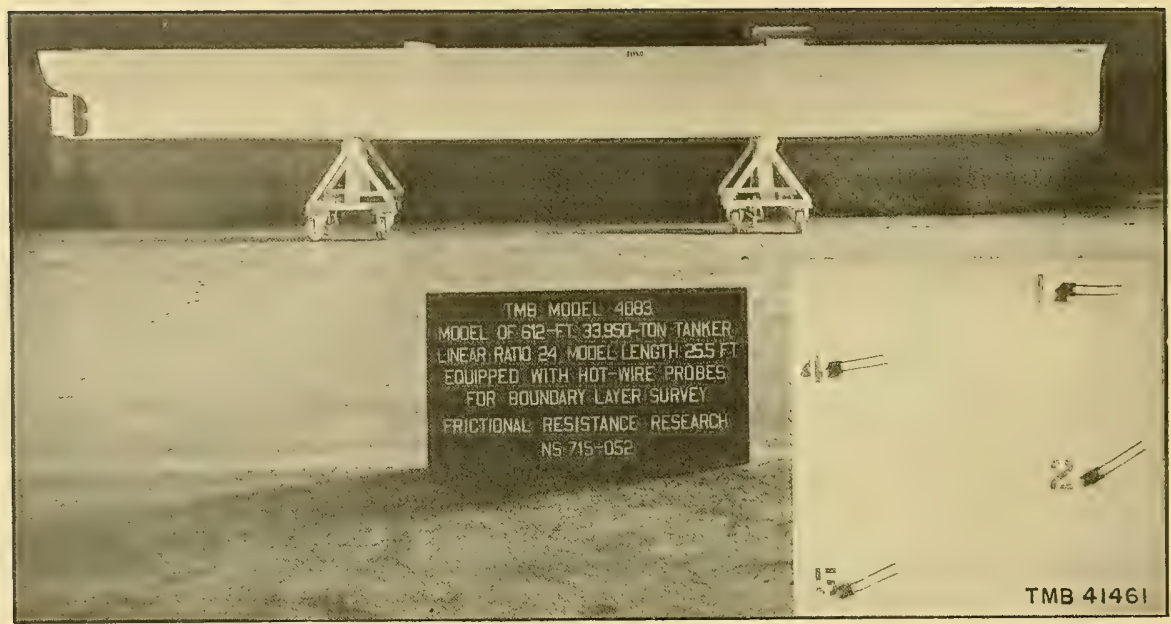

Figure 6 - TMB Model 4083 Showing Distribution of Hot-Wire Probes with Insert Enlargement of 4 Probes

the model showed turbulent flow. The second check consisted of moving a hotwire probe in and out of the boundary layer by means of a micrometer screw. When the wire was within 0.3 -inch of the surface the response of the wire was characteristic of turbulence. The intensity of turbulence decays toward the "edge" of the layer and beyond this the flow was found to be without fluctuation.

\section{TEST CONDITIONS}

Surveys of the boundary-layer flow were made under four conditions. For the first condition the model was towed without any turbulence stimulator. For the second, a series of tests were conducted in which a $1 / 8$-inch rod, held vertically in the water, was placed successively at 24, 48, and 192 diameters forward of the model stem, i.e., at 3 in., 6 in., and 24 in., respectively. For the third condition, records of the boundary-layer flow aft of a $0.032-$ inch trip wire, tacked around the girth of the model, were obtained. Finally, similar measurements were made with a fine-grain sand strip, 7/8-inch wide, in place of the trip wire. Location of these stimulators and their pertinent dimensions are given in Figure 9. For each of these conditions of stimulation the model was ballasted to correspond to the ship displacement of 33,950 tons of sea water at zero trim. The model was towed at 15 speeds in the range between 0.4 and 3.50 knots corresponding to 1.96 and 17.15 knots for the ship. 

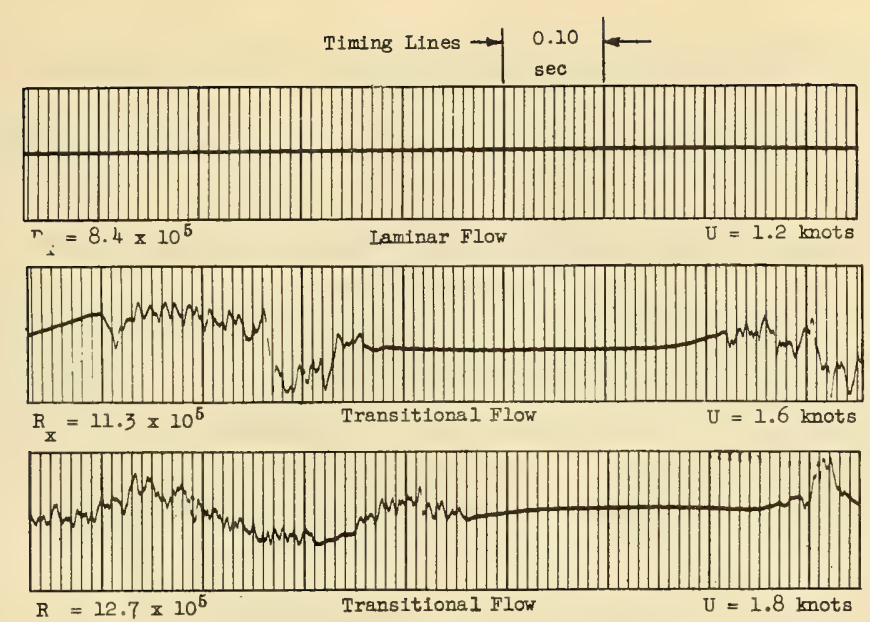

$\mathrm{x}$
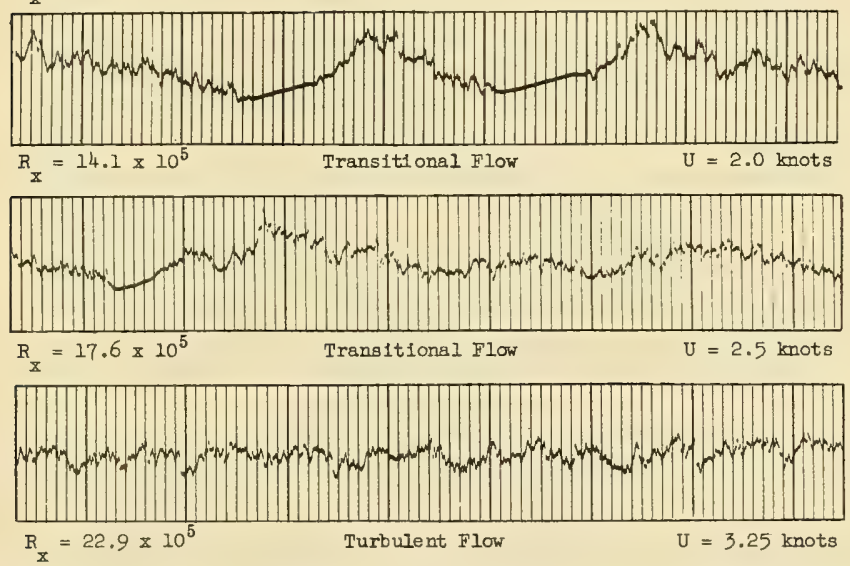

Figure 7 - Characteristic Oscillograms of the Development of the Turbulent Boundary Layer at Hot Wire 17 Without Artificial Turbulence Stimulation

The low speeds are of particular interest in that the development of the transition zone and the regression of the laminar area can be followed.

After the boundary-layer surveys the probes were removed from the model and resistance tests were made to obtain a record of the changes produced on the drag of the model by the use of the various stimulators. In all these tests care was taken to duplicate the conditions which were imposed for the boundary-layer surveys. It must be noted, however, that in order to install and to remove the trip wire and sand strip all of the ballast (3900 1b) 


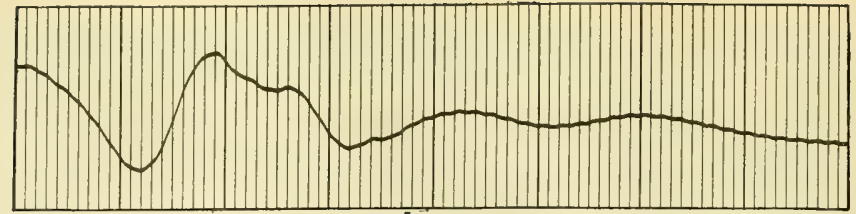

x-Reynolds number, $R_{X}=6.54 \times 10^{5} \quad$ Towing speed $U=0.50$ knot

Laminar Oscillations
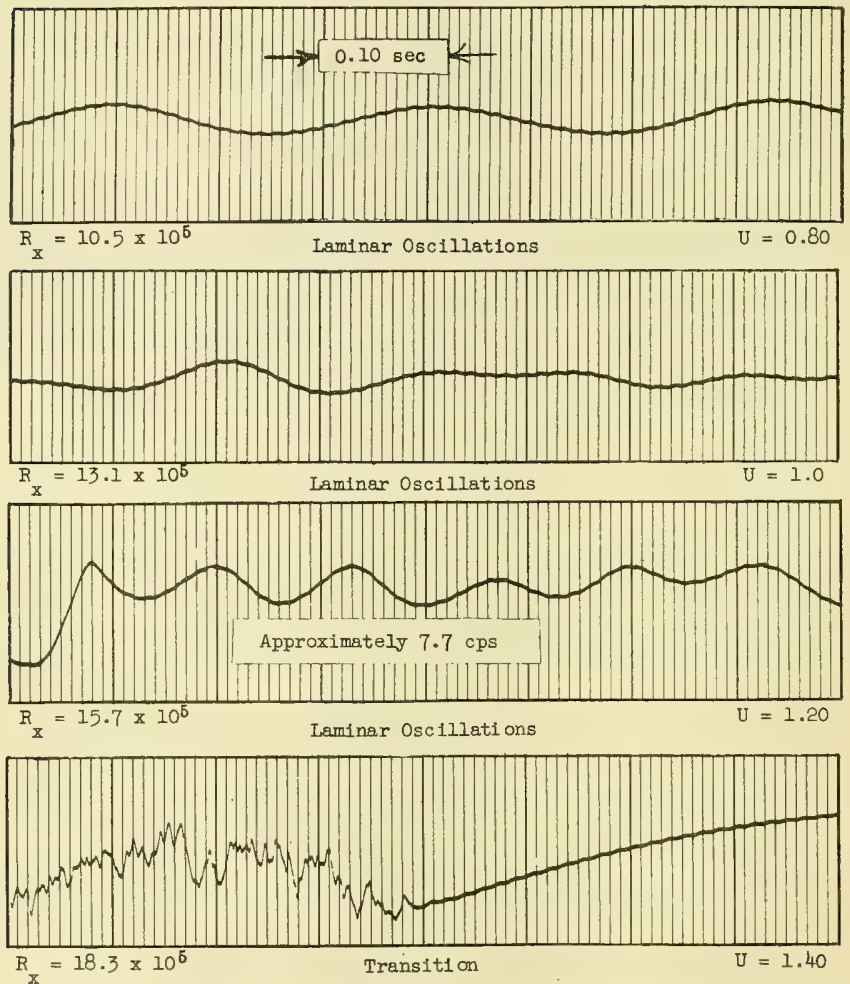

Figure 8 - Oscillograms of Oscillations in the Laminar Boundary Layer at 7.75 Ft from Bow and 1 Ft Above the Keel of Tanker Model 4083

had to be removed, the model taken out of the water, the stimulator changed and the reballasted model again connected to the dynamometer for the succeeding test. A uniform wa1ting period between runs was adhered to which provided a lapse of 15 minutes between the starts of successive runs. In all these tests an effort was made to conform to present practices for conducting resistance tests at the Taylor Model Basin. 


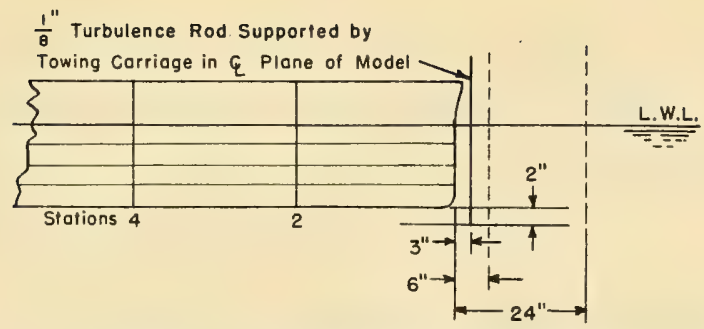

Figure 9a - Positions of Turbulence Rod, Corresponding to 24,48 , and 192 Rod Diameters Forward of Model Stem

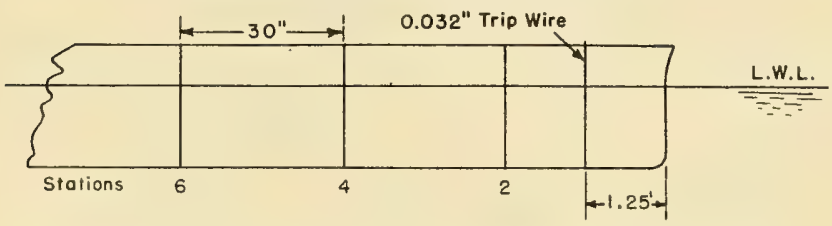

Figure $9 \mathrm{~b}$ - Location of Trip Wire at 5 Percent of Length from Bow

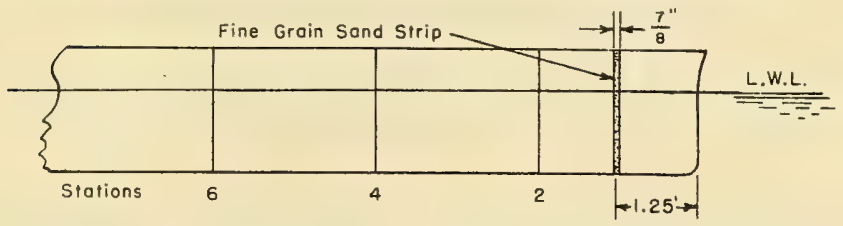

Figure 9c - Location of Sand Strip; Average Grain Diameter, 0.028 Inch

Figure 9 - Detalls of Devices Used to Stimulate A

Turbulent Boundary Layer on Tanker Model

\section{ANALYSIS OF RESULTS OF BOUNDARY-LAYER SURVEY}

\section{THEORETICAL BACKGROUND}

A well developed theory of the stability of laminar flow exists and may be put to use in the interpretation of results of these model experiments. It appears worth while at this point to give a brief summary of this theory. An extensive amount of literature has accrued during the past 70 years on the subject of laminar stability. A recent and very thorough treatment has been rendered by C.C. Lin ${ }^{4}$ and much work has also been done by Schlichting which is conveniently summarized in Reference 5 .

\section{STABILITY THEORY OF LAMINAR FLOW}

Modern theory holds that transition from laminar to turbulent flow is the result of a stability phenomenon. The most successful mathematical attacks on the problem have been those in which a small disturbing flow, or 
oscillation, is added to the basic laminar flow which is known to be well represented by the Navier-Stokes equations.

For two-dimensional flows of the boundary-layer type a periodic disturbance wave is specifled by

$$
\psi(\mathrm{x}, \mathrm{y}, \mathrm{t})=\phi(\mathrm{y}) \mathrm{e}^{i \alpha(x-c t)}
$$

where $\psi$ is the disturbing stream function,

$\phi$ is the amplitude of the disturbance flow ( $\phi$ is complex);

$\alpha$ is the wave number $\frac{2 \pi}{l}, l$ being the wave length, $c=C_{r}+i C_{i}$ where $C_{r}$ is the wave velocity and $C_{1}$ is the amplification factor,

$x$ is a coordinate measured from the leading edge of the body in the didirection of flow,

$\mathrm{y}$ is a coordinate measured perpendicular to the flow from the boundary of the body, and

$t$ is the time.

The following linearized disturbance differential equation in $\phi$ is then derived from the Navier-Stokes equations:

$$
[u(y)-c]\left[\phi^{\prime \prime}-\alpha^{2} \phi\right]-U^{\prime \prime} \phi=\frac{-1}{\alpha R}\left(\phi^{\prime \prime \prime \prime}-2 \alpha^{2} \phi^{\prime \prime}+\alpha^{4} \phi\right)
$$

where $u(y)$ is the dimensionless velocity distribution of the main flow, and $\mathrm{R}$ is a boundary layer Reynolds number defined by $\frac{U \delta^{*}}{\nu}$, $\delta^{*}$ being the displacement thickness and $v$ the kinematic viscosity of the fluid. All velocities have been referred to a velocity $U$ and all lengths to a boundary-layer displacement thickness $\delta^{*}$ so that Equation [2] 1s dimensionless. Primes indicate differentiation with respect to $\mathrm{y} / \delta^{*}$.

The problem becomes one of finding a relationship of the form

$$
c_{1}=g(\alpha, R)
$$

from which the curve of neutral stability $C_{1}=0$ may be drawn in the $\alpha, R$ plane. In this way the stable areas $\left(C_{1}<0\right)$ may be graphically separated from the values of $\alpha$ and $R$ which will give instability, $\left(C_{1}>0\right)$.

The results of such a calculation made by in for the Blasius flatplate flow are given in Figure 10. Here it is seen that below the lower critIcal Reynolds number $\frac{U \delta^{*}}{\nu}=420$ all disturbances are damped. The theory has been successfully checked by experiment; ${ }^{3}$ the agreement of theory and exper 1 ment is indicated in Figure 10.

Similar calculations made by Schlichting and Ulrich for boundarylayer flows with various pressure gradients are of great help in interpreting the flow about a ship model. They computed the stability regions for flows of 
the Pohlhausen type ${ }^{6}$ which are given by

$$
u=\left(\frac{12+\lambda}{6}\right) \frac{y}{\delta}-\frac{\lambda}{2}\left(\frac{y}{\delta}\right)^{2}-\left(\frac{4-\lambda}{2}\right)\left(\frac{y}{\delta}\right)^{3}+\left(\frac{6-\lambda}{6}\right)\left(\frac{y}{\delta}\right)^{4}
$$

where $\lambda=\frac{\delta^{2}}{\nu} \frac{\mathrm{dU}}{\mathrm{dx}}$, $\frac{\mathrm{dU}}{\mathrm{dx}}$ being the velocity gradient, and $\delta$ is the so-called Pohlhausen boundary layer thickness. ${ }^{6}$

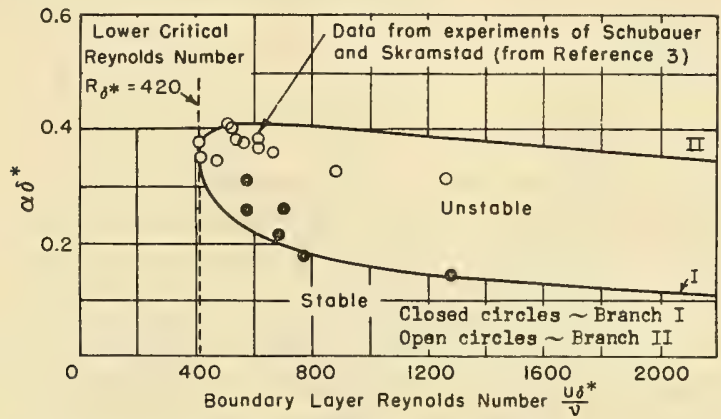

Figure 10 - Curve of Neutral Stability Calculated By Lin for Blasius' Flat Plate Flow (From Reference 4)

The stability calculations for varlous $\lambda$ have produced the relationship between lower critical Reynolds number and $\lambda$, as shown in Figure 11. Here it may be seen that decreasing pressure (increasing velocity, $\lambda>0$ ) in the direction of flow are favorable to the stability of the laminar layer and that increasing pressures $(\lambda<0)$ are unfavorable.

It must be pointed out that the theory does not predict the position of transition. The instabilitles which may arise take time to amplify to the state at which they produce transition. Hence it may be expected that the transition Reynolds number is much greater than the

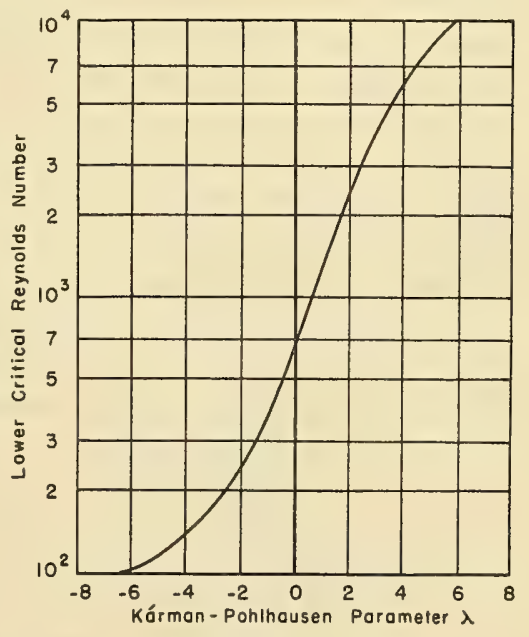

Figure 11 - Critical Values of $R_{8} *$ as a Function of the Velocity Gradient Parameter $\bar{\lambda}$ (Computed by Schlichting and Ulrich, see Reference 5) 
lower critical Reynolds number computed from this theory. The theory does not relate the onset of instability to surface roughness, nor predict the magnitude of the velocity fluctuations produced. However, the mathematical work clearly shows that only certain disturbances at sufficiently high Reynolds numbers will produce instability and also predicts the effect of pressure gradients on the stability of the flow. Many of the results obtained from the tests on the tanker model may be interpreted in the light of this theory.

QUALITATIVE ANALYSIS

Condition 1 - No Stimulation

The qualitative analyses of the boundary-layer flow on the tanker model without any stimulation are summarized in pictorial form in Figure 12. These results show, first of all, that a considerable portion of the wetted surface is covered by laminar flow, 20 percent at 0.5 knot and 3.3 percent at 3.5 knots. Further, it appears from the shape of the laminar region that transition occurs earlier near the free surface. Such a condition implies that more destabilizing influences are present here than at points below the surface. Destab1lizing effects may conceivably arise from additional vorticity generated at the free surface and also from surface waves which may be interpreted, by a Fourier analysis, to contain disturbances of all frequencies. As shown in the preceding section, the stability theory predicts that only certain types of disturbances will cause transition. Hence it appears more likely that with a wide spectrum of disturbance frequencies available to the boundary layer near the surface, transition will occur earlier here. It is expected that such influences as are peculiar to the free surface would decay exponentially with depth so that transition along deeper streamlines would occur farther along the body.

It must be noted in this case that the outlines of the regions of laminar, transitional, and turbulent flow are approximate because the determinations were made at discrete points. For example, no wires were placed very close to the water surface, and hence it is quite possible that there is a strip of transitional and turbulent flow near the surface extending farther forward than indicated in Figure 12. In addition, the boundary-layer patterns are in some instances given for a range of speeds. It is reasonable to assume that these patterns varied within these speed ranges. In view of the fixed hot-wire positions, however, such small changes that may have been present were not detected when they occurred between stations of observation. 

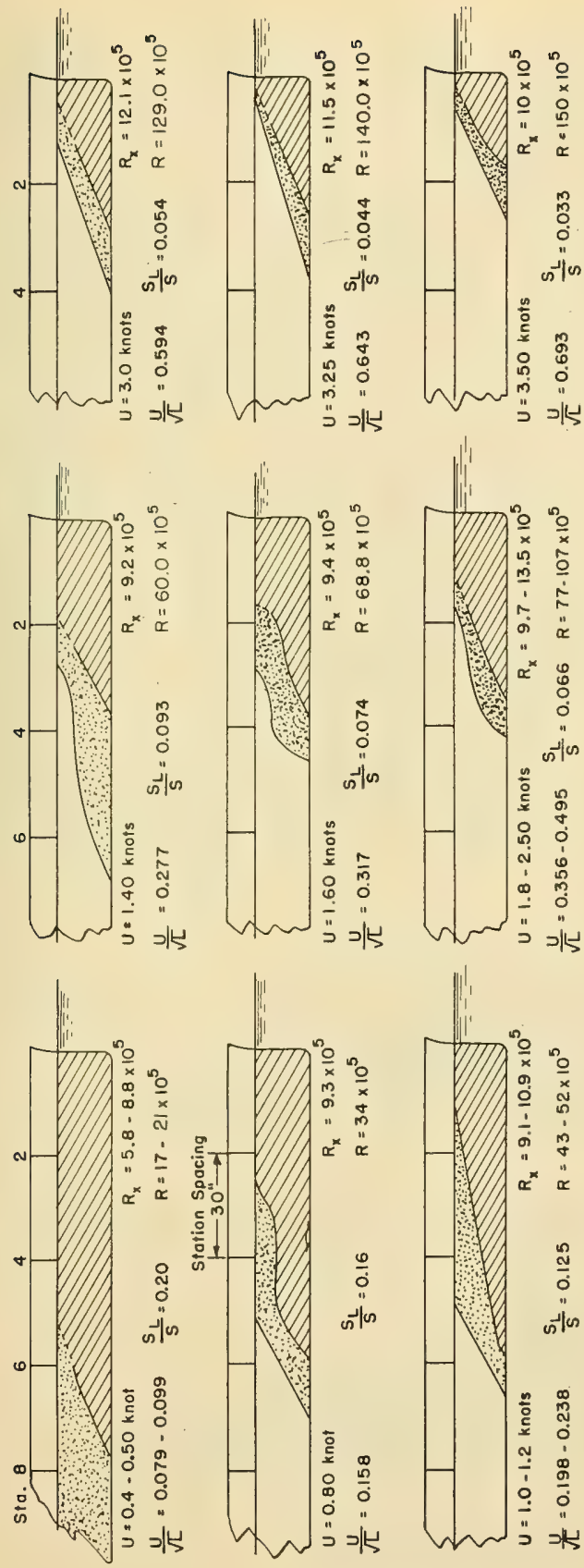

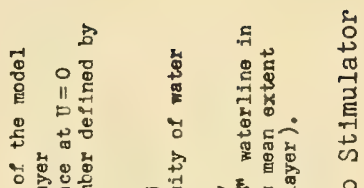

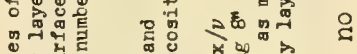

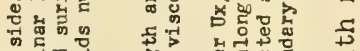

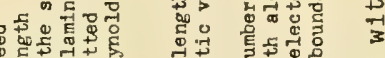

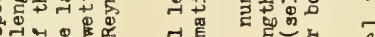
势

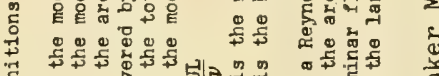

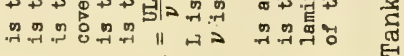

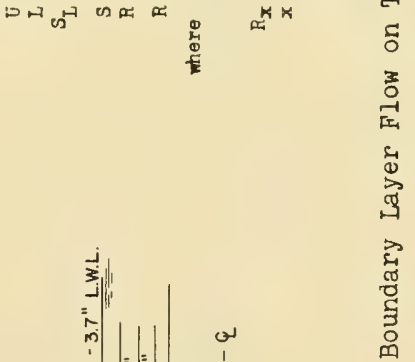


The manner in which the laminar area $S_{L}$ diminishes as the model Reynolds number increases is of considerable interest. The ratio of $\mathrm{S}_{\mathrm{L}}$ to the wetted surface $S$ of the model at rest is plotted against the Reynolds number in Figure 13. For comparison a hypothetical curve has been computed for a flat plate with the assumption that the Reynolds number of transition $R_{x}$ is constant at $10^{6}$ and that there are no disturbances arising from the plate eiges or the water surface. Admittedly, this latter assumption is an oversimplification and amounts to specifying the largest possible laminar region for a given $R_{x}$. This computed curve is a branch of an equilateral hyperbola and the curve of $S_{L} / S$ for the ship model has much the same shape between $\mathrm{x} / \mathrm{L}=0.35$ and 0.128 . In contrast, however, a wedge of the side area from the bow to $x / L=0.128$ remains constantly laminar between model Reynolds numbers 7.75 to $11.0 \times 10^{6}$. The area $S_{L}$ then continues to decrease for $R>11.0 \times 10^{6}$. This constancy of $S_{L}$ over a range of Reynolds numbers may be attributed to the stabilizing effect of the negative-pressure gradients which are known to exist over this portion of the hull and also to the fact that surface disturbances cannot be diffused rapidly enough to affect the region forward of Station 2. The fact that negative-pressure gradients extend over at least the first 10

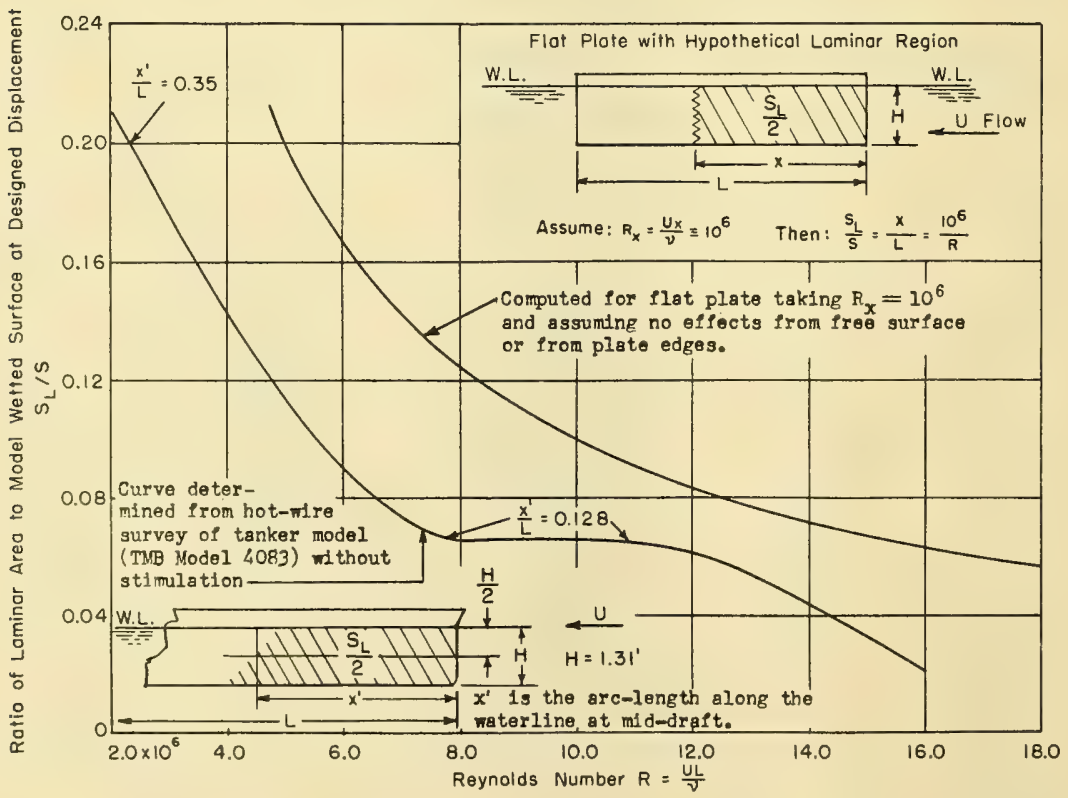

Figure 13 - Variation with Reynolds Number of Area Covered by Laminar Boundary Layer 
percent of the model length has been shown ${ }^{7}$ for models of U-shaped bow sections. The reference cited reports similar boundary surveys made by visual methods at the National Physical Laboratory in England. The conclusions deduced from British tests, , 8 are largely substantiated by the present hot-wire survey. Furthermore, exploratory experiments made by W. Hinterthan at the Taylor Model Basin-using a chemical technique to determine the character of the boundary layer flow on models and flat plates-have also confirmed the general shape of the laminar region as found by the hot-wire method.

An additional result from the TMB survey is that the flow on the bottom, $3 \mathrm{ft}$ from the bow and 4 inches off the centerline (E), was turbulent at speeds as low as $0.8 \mathrm{knot}$, or $R^{\prime}=3.44 \times 10^{6}$. At this value the mean position of transition on the side was found to be much farther aft at $x=6.9$ $\mathrm{ft}$. Evidently the flow immediately enters an unstable region just after rapid passage around the turn of the bilge forward of Station 2. Th1s effect is also noted in the British paper.

A curlous result was obtained from the first series of tests in which the model was towed without turbulence stimulation. Analysis of the hot-wire responses produced sketches of the regions of the laminar and turbulent boundary layers at each speed similar to that shown in Figure $74 a$. It was suggested that these anomalous results were caused by minute paint particles. Upon close examination of the surface small regions of roughness were found where the model had been repalred with shellac. The rough spots of

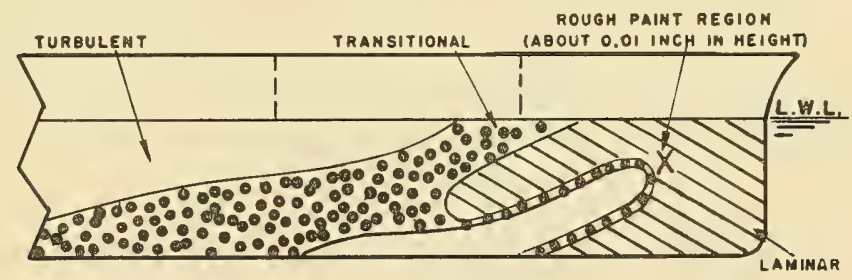

Figure 14a - Turbulent Pattern Caused by Paint Roughness

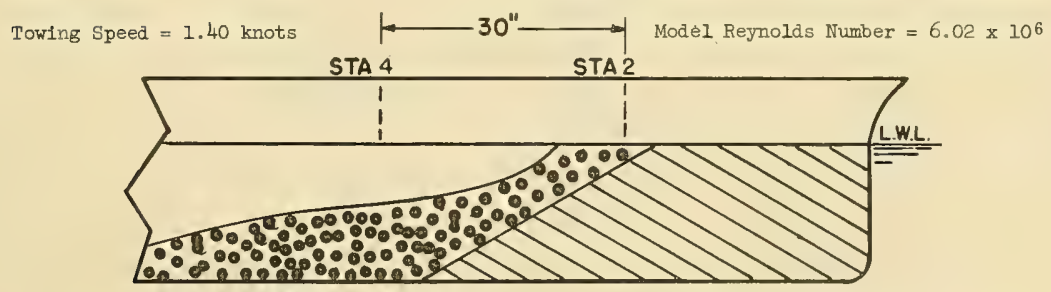

Figure 14b - Laminar Pattern Found After Rough Paint Region was Smoothed

Figure 14 - Boundary-Layer Flow Patterns Showing the Effect of Small Surface Roughness 
height not exceeding $0.01-\mathrm{in}$. were found to be directly in the line of flow of the "peninsula" of turbulence shown in Figure 14a. The surface was carefully rubbed down and refinished and the entire test repeated. The repeat test gave patterns of which Figure $14 \mathrm{~b}$ is typical. Dryden ${ }^{9}$ has reported a simllar phenomenon. He found that a thin layer of dust on a flat plate tested in a wind tunnel was sufficient to cause an anomalous boundary-layer flow-pattern. These results clearly show that in order to obtain repeatable data the surface of the model must be kept extremely smooth and clean.

\section{Condition ? - Stimulation by Rods}

Three surveys were made with a 1/8-inch-diameter circular cylinder or rod placed vertically in the longitudinal $\mathbb{E}$ plane of the model at distances forward of the stem of 24,48 , and 192 rod diameters (3, 6, and 24 inches). They produced the distributions of boundary layer flows shown in Figure 15. From these sketches 1 is seen that at a distance of 48 diameters the rod stimulates the boundary layer more effectively than at the other positions. It is interesting to note that, with the rod 192 diameters forward, at speeds greater than 0.8 knot the shapes of the laminar and transitional areas are different from those found for the other rod settings, indicating stronger stimulation in the neighborhood of the forefoot than at the water surface. From this it would appear that the turbulence produced by the rod decays more rapidly at the surface than at keel depth. However, since no information on such phenomena is believed to be available at this time no authoritative statement can be made. It is expected that quantitative measurements of the decay of turbulence behind rods which are to be made at the Taylor Model Basin will provide sufficient data to determine the best position of the rod for adequate stimulation.

\section{Condition 3 - Stimulation by. Trip Wire}

Results of the boundary-layer survey made with the 0.032 -inch trip wire in place are summarized in Figure 16. The rapid change in the position of transition behind the trip wire agrees with the result obtained from measurements in a water tunnel on two bodies of revolution. ${ }^{10}$ A plot of the variation of the minimum distance of transition from the stem with wire Reynolds number from the tanker test is given in Figure 17 together with curves deduced from the data given in Figure 13 of Reference 10. Both sets of data exhibit similar change in the position of transition with wire Reynolds number. The local wire Reynolds number increases with depth on the ship model because of 

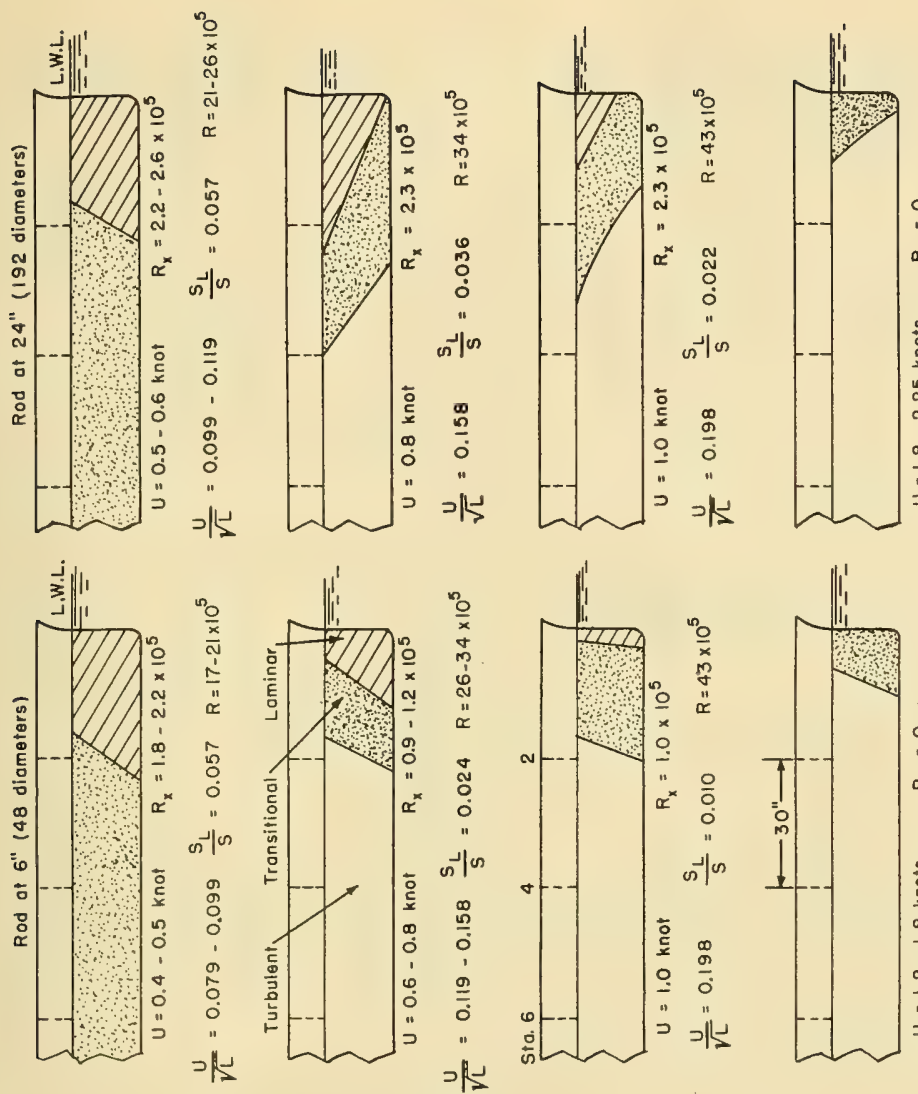

0
$\frac{0}{x}$
0
0
$i$
11
11

ठ

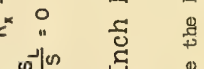

\& م

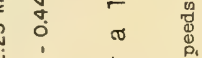

in $\overrightarrow{0}_{m}+$

"

ᄀ ग

वृत्य है

늘 융

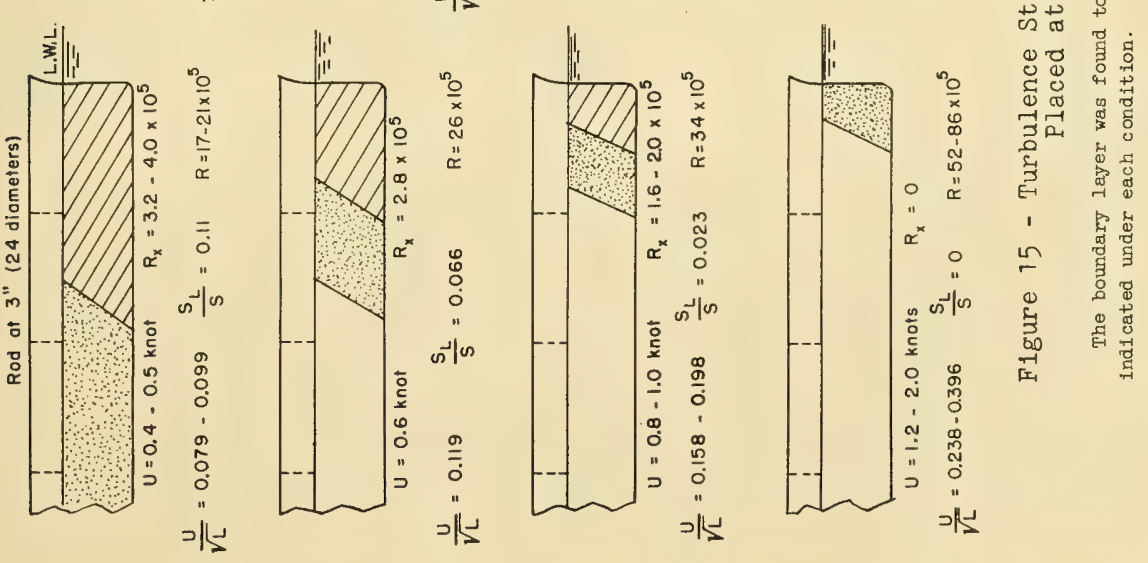



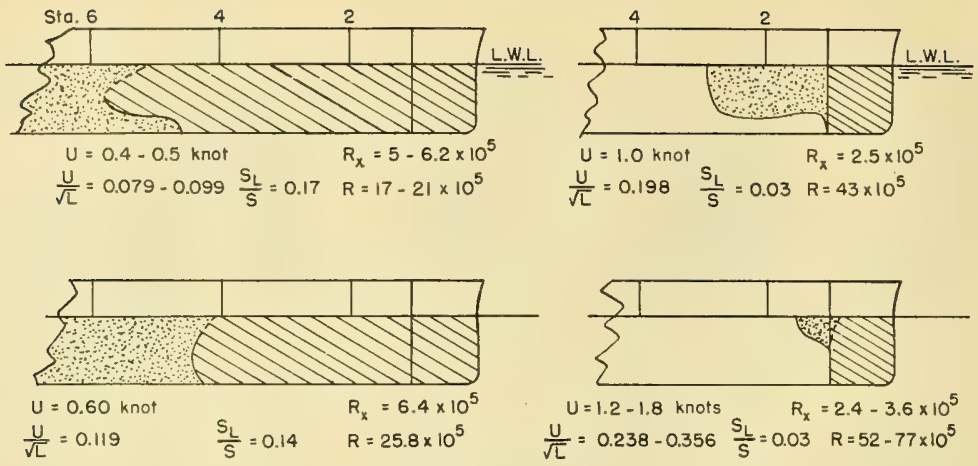

$0.032^{\text {" Trip Wire Around Girth } 7}$

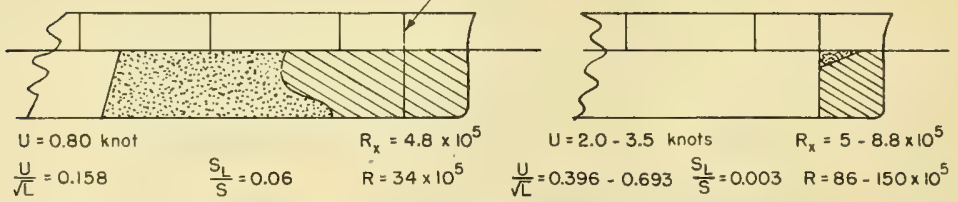

Figure 16 - Boundary Layer Flow Conditions on Tanker Model with Trip Wire as Turbulence Stimulator

the greater flow velocity toward the turn of the bilge. This probably explains the observed pattern of transition shown in Figure 16 where it is seen that transition occurs closer to the stem with increasing depth along the hull.

Condition 4 - Stimulation by Sand Strip

Data obtained from the boundary-layer survey made with the finegrain sand-strip are summarized in Figure 18. The pattern of the flow aft of the sand strip at low speeds was found to be considerably different from that obtained with the trip wire.

\section{COMPARISON OF EFFECTIVENESS OF VARIOUS STIMULATORS}

A summary of the boundary layer surveys made with the various methods of stimulation is given in Figure 19. Here it may be seen that the 1/8inch rod at 48 diameters is more effective in producing a turbulent boundary layer than any of the other devices. However, it must be remembered that this is a qualitative study and hence there is no guarantee that the intensity and scale of turbulence induced by the rod are of the proper magnitude. Quantitative determination of the intensity and scale of turbulence under basin 


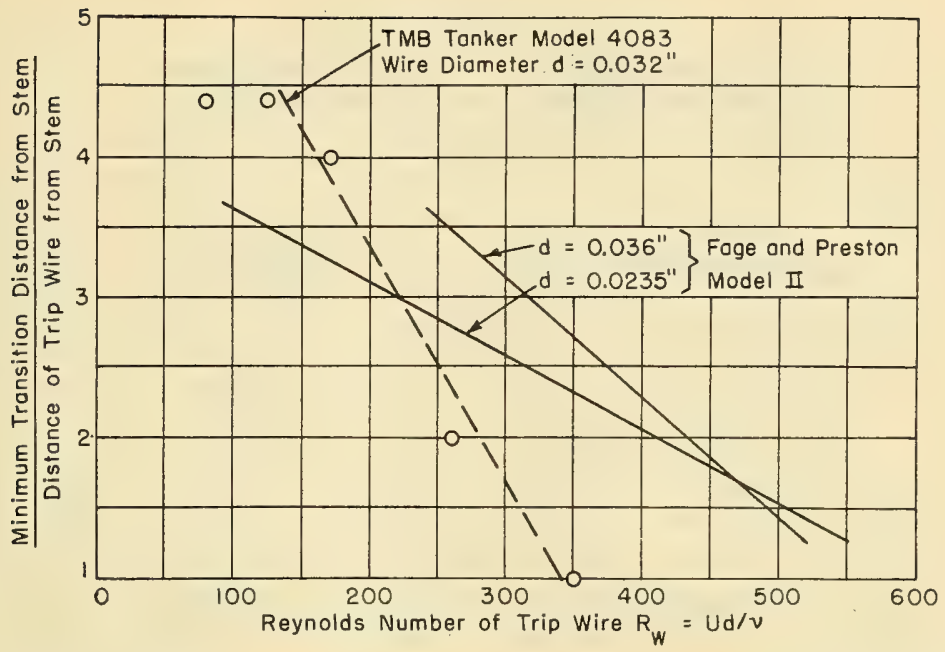

Figure 17 - Comparison of the Position of the Onset of Transition on TMB Tanker Model and on a Body of Revolution

The trip wire Reynolds number is based upon the free-stream speed U for both models.

conditions cannot be accomplished with the hot-wire apparatus at the present state of development. It is, nevertheless, important to be able to delineate the regions of laminar, transitional, and turbulent flow and for this reason the qualitative application of the hot wire is extremely useful. In addition, the results of the survey may be used to obtain a numerical estimate of the error or decrement in the frictional resistance of the ship model, as shown in the next section of this report.

QUANTITATIVE ANALYSIS OF HOT-WIRE DATA

An estimate of the decrement or "error" in the frictional resistance of the ship model can be obtained from the qualitative determination of the boundary-layer flow. The formula used to estimate the frictional resistance of any model expresses the turbulent frictional drag of a flat plate of the same length and wetted surface and towed at the same Reynolds number as the model. Hence the region on the model which is covered by laminar flow does not contribute as much resistance as it would were it covered by a turbulent layer. The decrement in the frictional resistance may be taken as the difference between the turbulent and the laminar drag of that region of the hull which has been found to be covered by a laminar boundary layer. 

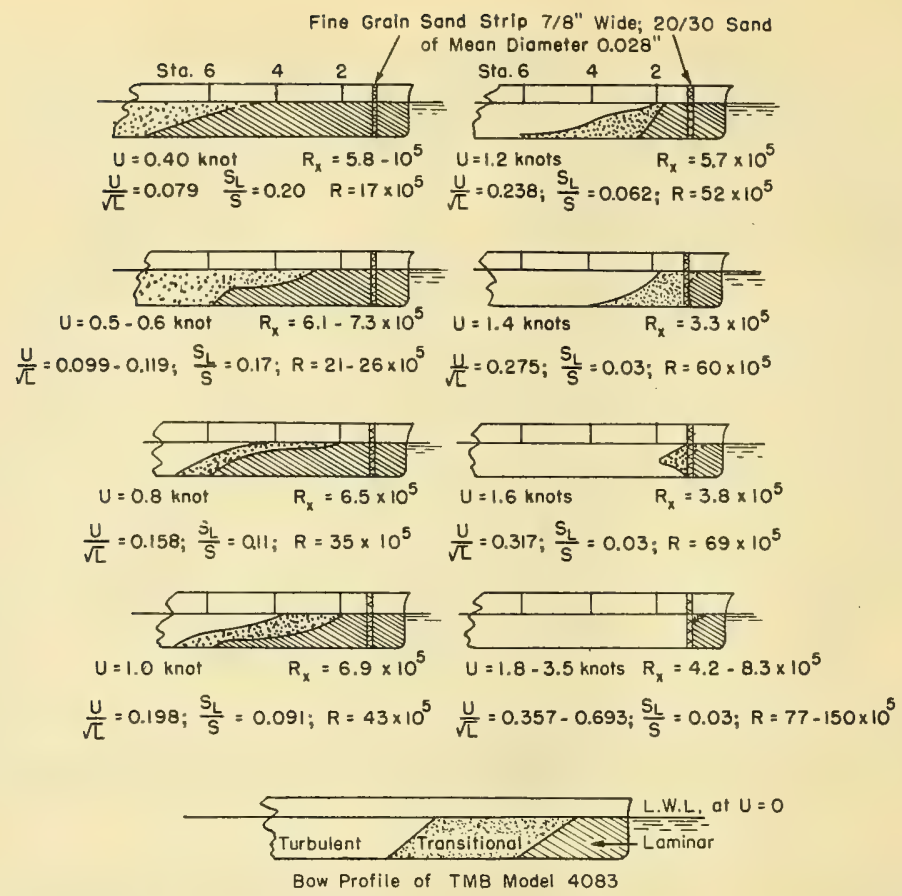

Figure 18 - Boundary Layer Flow Conditions on Tanker Model with a Sand Strip as Turbulence Stimulator

Definitions of symbols are given in Figure 10.

A simplified expression for the decrement in frictional resistance may be obtained from the following exact expression:

$$
\xi_{\mathrm{m}}=\frac{\int_{S_{\mathrm{L}}}\left(\tau_{\mathrm{m}}^{\prime}-\tau_{\mathrm{m}}\right) \cos \phi \mathrm{ds}}{\int_{S} \tau_{\mathrm{m}}^{\prime} \cos \phi d s}
$$

where $\xi_{\mathrm{m}}$ is the ratio of the decrement of the model frictional resistance to the total model turbulent frictional resistance,

$\tau_{m}$ is the laminar shearing stress,

$\tau^{\prime}{ }_{m}$ is the turbulent shearing stress on the model,

ds is an element of model wetted area,

$\phi$ is the direction angle between the longltudinal centerline of the model and the shear force,

$\mathrm{S}_{\mathrm{I}}$ is the hull area covered by a laminar boundary layer, and

$S$ is the wetted surface of the model at $U=0$. 


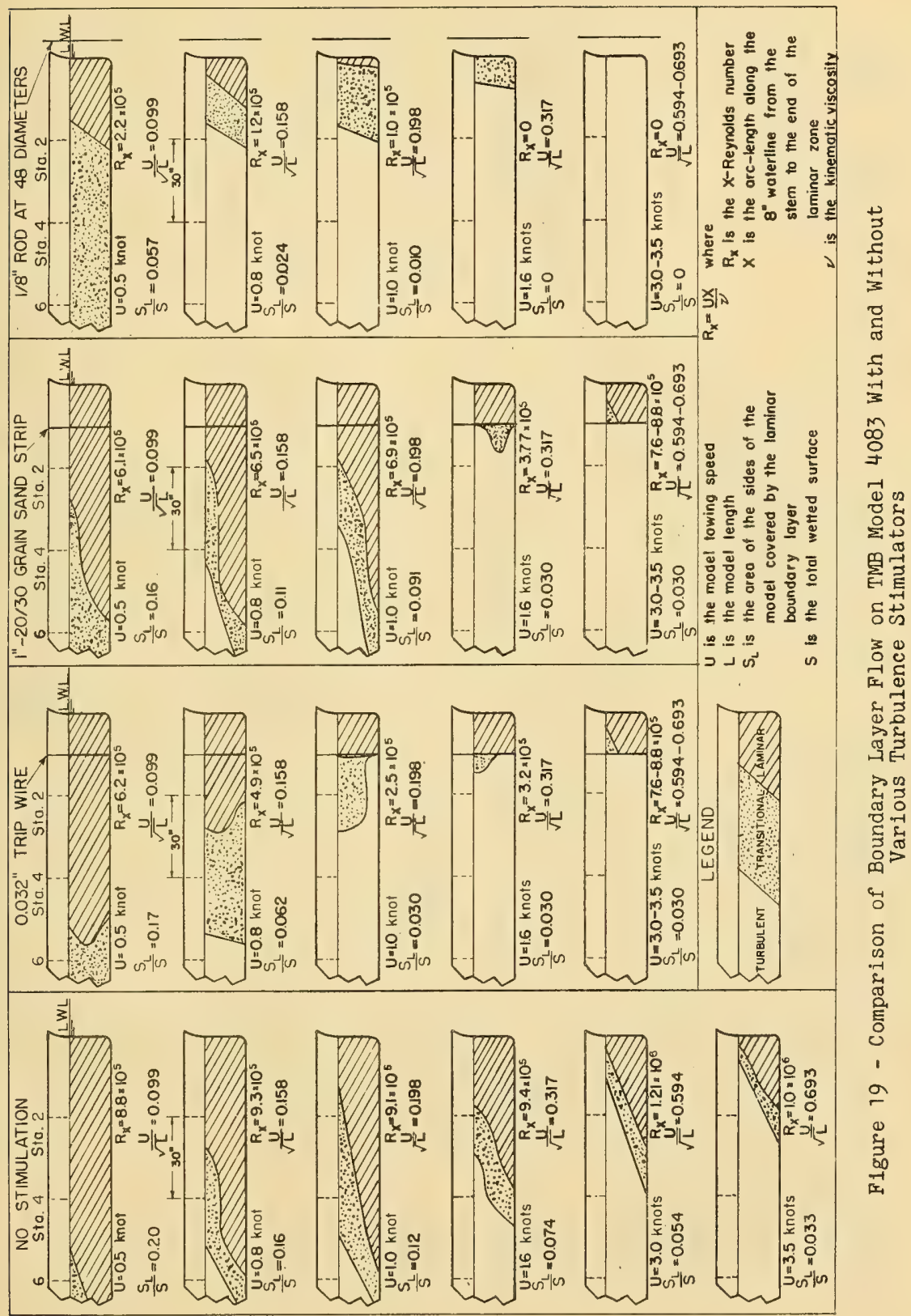


It is not possible to calculate $\xi_{\mathrm{m}}$ from [4] without detailed knowledge of the varlation of $\tau^{\prime}{ }_{m} ; \tau_{m}$, and $\phi$ over the entire model. The usual approximation must be employed, viz., that the integral of the shear forces over the hull is equal to the drag of a flat plate of the same wetted surface towed at the same Reynolds number. Since only the ratio of the integrals is ciesired this approximation to the exact ratio should be good. Therefore $\xi_{\mathrm{m}}$ may be approximated by the decrement for a flat plate $\xi$, that is

$$
\xi_{\mathrm{m}} \approx \xi=\frac{\int_{S_{L}}\left(\tau^{\prime}-\tau\right) d s}{\int_{S} \tau^{\prime} \mathrm{ds}}
$$

where $\tau^{\prime}$ and $\tau$ are the shearing stresses for a flat plate in turbulent and laminar flow respectively.

Equation [5] will be expressed later in terms of the Schoenherr frictional-resistance coefficient but at first it is desirable to obtain $\xi$ as a simpler function of the Reynolds number, inasmuch as the Schoenherr coefficient cannot be written in explicit form. To obtain an elementary form for $\xi$, the law of Blasius for the laminar shearing stress and the Prandtl-von Kármán formulation ${ }^{11}$ for turbulent shearing stress are assumed:

$$
\tau=0.332 \sqrt{\frac{\mu \rho U^{3}}{X}} \text { (for laminar flow) }
$$

and

$$
\tau^{\prime}=0.0296 \rho U^{2}\left(\frac{\nu}{U X}\right)^{1 / 5} \text { (for turbulent flow)* }
$$

where $\mu$ is the absolute or dynamic viscosity of the fluid,

$\rho$ is the mass density of the fluid,

$U$ is the speed,

$X$ is the distance from the leading edge, and

$v$ is the kinematic viscosity of the fluid.

Substituting Equations [6] and [7] into [5] and integrating gives

$$
\xi=\frac{S_{L}}{S}\left(\frac{R}{R}\right)^{-0.5} \quad\left(1-18 R_{x}^{-0.3}\right)
$$

\footnotetext{
*It will be noted that the numerical coefficient in the expression for $\tau^{\dagger}$ is given in Reference 11 as 0.0288 . Schllchting ${ }^{5}$ has recommended the slightly larger coefficlent to give better agreement with experimental data.
} 
where $R_{x}$ is the $x$-Reynolds number,

$x$ is the linear extent of the laminar region on the flat plate taken to be the arc length along the half-draft water line to the boundary of the laminar region on the ship model,* and

$R$ is the model Reynolds number.

For a flat plate without disturbances arising from the lower edge or from the water surface we may assume that the transition Reynolds number $R_{x}$ is a constant. From this it follows that:

$$
\frac{S_{L}}{S}=\frac{R_{x}}{R}
$$

So that Equation [8] becomes

$$
\xi^{\prime}=\left(\frac{R_{x}}{R}\right)^{0.8}\left(1-18 R_{x}^{-0.3}\right)
$$

Since on this ship model transition occurs, on the average, at $R_{x}=10^{6}$ Equation [10] reduces to

$$
\xi^{\prime}=4.52 \times 10^{4} R^{-0.8}
$$

Thus for the hypothetical case of the flat plate the decrement of frictional resistance in percent of the total turbulent frictional resistance decreases almost hyperbolically with Reynolds number.

However, the Reynolds number of transition $R_{x}$, and hence $S_{L}$ is from a consideration of theory and experience, a function of the pressure gradients, disturbances arising at the water surface, and the characteristics of the freestream turbulence. Roughness of the model surface would also greatly affect the location of transition. However, only hydraulically-smooth surfaces are considered in the foregoing derivations.

Since $S_{L} / S$ and $R_{X}$ have been determined from the hot-wire surveys on the tanker model at various values of $R$, $\xi$ for the model computed from Equation [8] may be compared with $\xi$ ' for the flat plate, computed from Equation [11]. These values are plotted as functions of model Reynolds number in Figure 20. Included in the same figure is the decrement in terms of the Schoenherr frictional resistance coefficients as defined by the following equation:

*Although this definition is arbitrary it is belleved to give an average value for the linear extent of the laminar region which is sufficiently accurate for the approximate calculations made in this report. 


$$
\bar{\xi}=\frac{S_{L}}{S}\left[\frac{C_{f}^{\prime}\left(\frac{U_{x}}{\nu}\right)-C_{f L}\left(\frac{U x}{\nu}\right)}{C_{f}^{\prime}\left(\frac{U L}{\nu}\right)}\right]
$$

where $\bar{\xi}$ is the decrement computed using Schoenherr coefficients, $C_{f}^{\prime}$ is the Schoenherr frictional coefficient, and $C_{f L}=1.328 R_{x}^{-1 / 2}$ is the Blasius laminar frictional coefficient. As was to be expected, the agreement between Equations [8] and [12] 1s very good. However, for the sake of consistency with present practice, values of $\bar{\xi}$ determined from the Schoenherr coefficients will be used. The Schoenherr coefficients are conveniently tabulated for various Reynolds numbers in a Taylor Model Basin report. ${ }^{12}$

In a similar way a quantitative estimate of the effectiveness of the various stimulating devices may be obtained by calculating the increase in the frictional resistance of the model with turbulence stimulation over the frictional resistance without any stimulation. This may be expressed in terms of

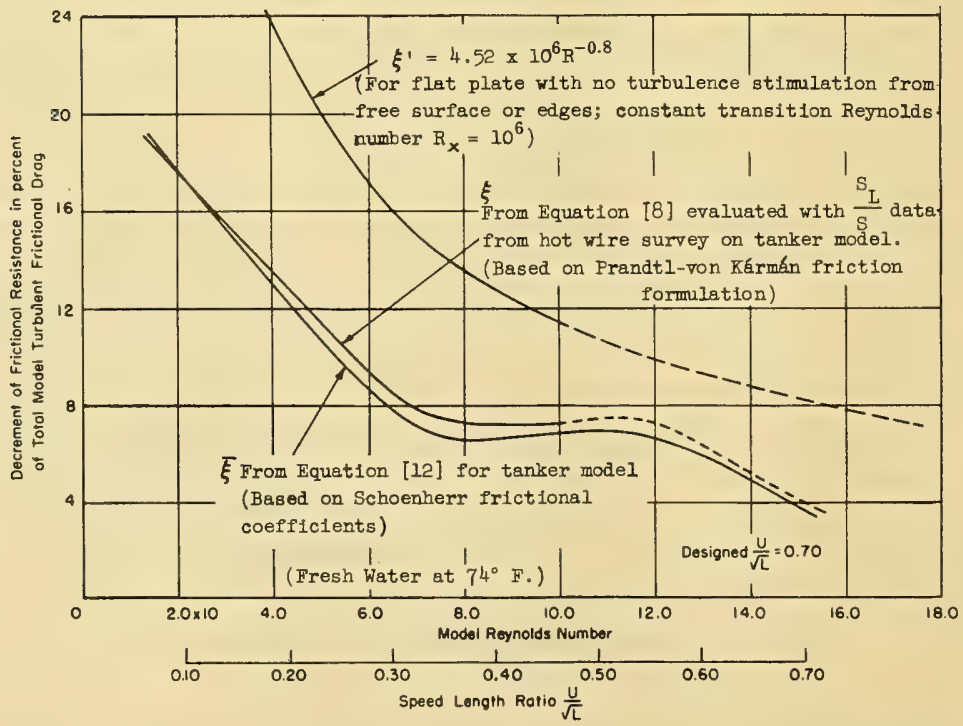

Figure 20 - Decrement of Frictional Resistance with no Stimulation 
the decrements calculated for the nonstimulated and the stimulated condition, viz.,

$$
\frac{\Delta C_{f}^{*}}{C_{f}^{\prime}}=\bar{\xi}_{0}-\bar{\xi}_{S}
$$
where $\frac{\Delta C_{f}^{*}}{C_{f}^{\prime}}$ is the ratio of the increase in frictional resistance to the equivsurvey data,

$\bar{\xi}_{0}$ is the computed decrement of resistance caused by the laminar flow over the model without turbulence stimulation, and

$\bar{\xi}_{S}$ is the computed decrement of frictional resistance caused by the laminar flow which persists when the model is towed with a stimulator.

Curves of $\Delta C_{f}^{*} / C_{f}^{\prime}$ have been drawn on Figure 21 where it may again be observed that the turbulence rod appears to be relatively better than the other devices which were tested. It should be noted, however, that the values of $\Delta \mathrm{C}_{\mathrm{f}}^{*}$ at Low Reynolds numbers $\left(R<6 \times 10^{6}\right)$ are probably somewhat high because of the extensive region of transitional flow obtained with turbulnnce stimulation, as shown in Figure 19. No allowance has been made for the decrement arising from transitional flow in any of the calculations.

It now remains to show that the predicted increases in resistance obtainea from the boundary-layer surveys can be correlated with the increases measured by the towing dynamometer under the same conditions of stimulation.

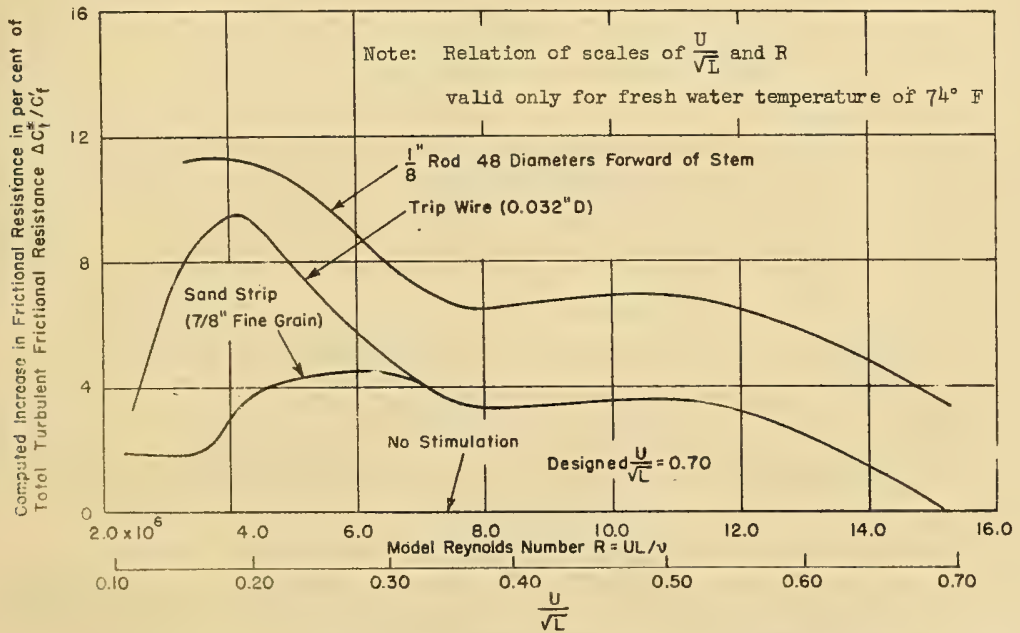

Figure 21- Curves of Computed Increase in Frictional Resistance of Tanker Model Determined from Boundary-Layer Surveys with Various Stimulators 


\section{QUANTITATIVE ANALYSIS OF RESISTANCE TEST DATA}

WITH AND WITHOUT STIMULATION

The resistance test of a model provides a relationship between the total measured resistance $R_{t}$ and the towing speed $U$. As is well known the model towing speed is determined so that the Froude number, $\mathrm{J} / \sqrt{\mathrm{gL}}$, is the same in model and prototype dimensions. Froude's basic assumption as used today may be stated:

$$
\frac{R_{t}\left(\frac{U}{\sqrt{g L}}, \frac{U L}{\nu}\right)}{\frac{\rho}{2} S U^{2}}=\frac{R_{r}\left(\frac{U}{\sqrt{g L}}\right)}{\frac{\rho}{2} S U^{2}}+\frac{R_{f}\left(\frac{U L}{\nu}\right)}{\frac{\rho}{2} S U^{2}}
$$

or

$$
c_{t}=c_{r}+c_{f}
$$

where $R_{t}$ is the total resistance,

$\mathrm{R}_{r}$ is the so-called residuary resistance,

$R_{f}$ is the frictional resistance of the model,

$\rho$ is the mass density of the fluid,

$g$ is the acceleration due to gravity, and

$\mathrm{C}_{t}, \mathrm{C}_{\mathrm{r}}, \mathrm{C}_{\mathrm{f}}$ are the corresponding resistance coefficients.

In order to scale the residuary resistance the model must be towed at the same Froude number, * whereas to scale the frictional resistance the model must be towed at the same Reynolds number. This incompatible situation is circumvented by assuming that the frictional resistance of model and prototype may be calculated from the empirical laws for the frictional resistance of flat planks having the same wetted surface and towed at the same Reynolds numbers. A summary of the experimental and theoretical work in regard to flat-plate resistance has been given by Davidson. ${ }^{13}$ The detalls of the method used at the Model Basin are reported in Reference 12.

Although the use of a device to stimulate turbulence represents an effort to make the flow about the model similar to that about the prototype, the stimulator itself may introduce additional forces or modify the flow to produce effects on the drag of the model which are undesirable. A sand strip

\footnotetext{
*Actually, Froude's assumption is an oversimplification because the residuary resistance as calculated involves quantities which are not independent of the Reynolds number. The residuary resistance is the sum of the wave resistance, the viscous pressure drag and the additional frictional forces which arlse from the curvature of the form and the surface roughness. Each of these terms is dependent more or less on the model Reynolds number.
} 
and a trip wire have drag forces of their own and a turbulence rod produces a wake which alters the pressure distribution over the bow and also produces some effect on the wave resistance.

Tests with and without a turbulence stimulator give changes in total measured resistance $\Delta R_{t}$ which may be written

$$
\Delta R_{t}=\Delta R_{f}+\Delta R_{r}+D_{s}
$$

where the $\Delta$ 's indicate the actual changes in the various resistances and $D_{S}$ is the drag (or undesirable effect on drag) of the stimulator itself.

For purposes of fairing the data it is convenient to compute a socalled residuary-resistance coefficient by approximating the friction drag of the model with flat-plate friction data. Then

$$
C_{r}=\frac{R_{t}-R_{f}^{\prime}}{\frac{\rho}{2} S U^{2}}
$$

where $R_{f}^{\prime}$ is the resistance of a flat plate at the model Reynolds number and having the same length and wetted surface as the model. The change in the measured total model resistance with turbulence stimulation is then reflected as a change in the computed residuary-resistance coefficient or $\Delta C_{r}=\Delta C_{t}$. Equation [15] may be transposed and put into nondimensional form to give

$$
\frac{\Delta \mathrm{C}_{\mathrm{f}}}{\mathrm{C}_{\mathrm{f}}^{\prime}}=\frac{\Delta \mathrm{C}_{\mathrm{t}}}{\mathrm{C}_{\mathrm{f}}^{\prime}}-\frac{\Delta \mathrm{R}_{\mathrm{r}}+\mathrm{D}_{\mathrm{S}}}{\mathrm{R}_{\mathrm{f}}^{\prime}}
$$

where $C_{f}^{\prime}$ is the Schoenherr frictional-resistance coefficient for flat plates It is usually assumed that the total increase in resistance with turbulence stimulation is due entirely to a change in the frictional resistance, or $\Delta \mathrm{R}_{r}=0$. This is a convenient and necessary assumption since it would be extremely difficult to estimate $\Delta \mathrm{R}_{\mathrm{r}}$ with accuracy.

The Prandtl assumption that the turbulent boundary layer behaves as though it started at the leading edge may be applied with particular confidence in the case of large models since the transition region is relatively close to the bow. Hence the flow over the after portion of the model would not be affected appreciably by the stimulation of turbulence and the residuary resistance will be nearly unaffected. The assumption that $\Delta \mathrm{R}_{\mathrm{r}}=0$ is then quite acceptable. An attempt can be made to estimate $D_{S}$, however, at least in the cases of stimulation with trip wire and sand strip. 
CORRECTION FOR DRAG OF A TRIP WIRE

Experiments conducted by $H$. Schlichting ${ }^{14}$ have shown that the increment of drag induced by an isolated roughness (small protrusion) in the boundary layer of a flat surface may be closely approximated by the drag of the same roughness placed in a free stream where the speed is equal to the boundary-layer velocity at a distance from the surface equal to the helght of the roughness. The drag of a trip wire may therefore be approximated by

$$
\mathrm{D}_{\mathrm{S}}=\frac{\rho}{2} \mathrm{C}_{\mathrm{D}} \mathrm{d} l \mathrm{u}^{2}
$$

where $u$ is the speed in the boundary layer at a distance of the wire diameter d from the surface,

$C_{D}$ is the drag coefficient of an infinite cylinder subjected to the free stream velocity $U=u$, and

$l$ is the wire length.

The velocity u may be conveniently estimated from Pohlhausen's original approximation ${ }^{6}$ for the laminar velocity distribution, which is

$$
\frac{u}{U}=\frac{2 y}{\delta}-\left(\frac{y}{\delta}\right)^{2}
$$

where $y$ is the distance along a normal to the surface and $\delta$ is the boundary layer thickness, 1.e., the value of $y$ at which $u=0.99$.

The boundary-layer thickness which is derived for this velocity distribution is given by the formula:

$$
\delta=x \sqrt{\frac{30}{\mathrm{R}_{\mathrm{x}}}}
$$

where $x$ is the longitudinal distance from the leading edge, and $R_{x}$ is the $x$ Reynolds number, $\mathrm{Ux} / \nu$.

To compute the boundary layer velocity $u$ at the height of the "roughness" let $y=d$ in Equation [19]. Then

$$
\frac{\mathrm{u}}{\mathrm{U}}=\frac{2 \mathrm{~d}}{\delta}-\left(\frac{\mathrm{d}}{\delta}\right)^{2}
$$

Since $d / \delta$ varies between 0.11 and 0.17 between towing speeds of 1.0 and 3.5 . knots it was considered sufficiently accurate to drop the square term and use

$$
\frac{\mathrm{u}}{\mathrm{U}} \approx \frac{2 \mathrm{~d}}{\delta}
$$


The equation for the wire drag as a fraction of the computed frictional resistance of the model is:

$$
\frac{D_{S}}{R_{f}^{\prime}}=\frac{2}{15} \frac{C_{D}}{C_{f}^{\prime}} \frac{d^{3} l R}{x L S}
$$

where $R$ is the model Reynolds number and $L$ is the model length. As a consequence of Equation [22] the smallest possible wire for adequate stimulation should be used, since the drag of the wire varies directly as the cube of its diameter.

For the range of wire Reynolds number, $1.5 \times 10^{2} \leqq \frac{U d}{\nu} \leqq 10^{3}$ the value of $C_{D}$ is found to be about 1.2, (see; e.g., Reference 15). Substituting the values, $d=0.00267 \mathrm{ft}, l=4 \mathrm{ft}, S=128.8 \mathrm{ft}^{2}, x=1.25 \mathrm{ft}$ and $\mathrm{L}=25.5 \mathrm{ft}$ into Equation [22] and inserting the results into Equation [17] gives

$$
\frac{\Delta C_{f}}{C_{f}^{\prime}}=\frac{\Delta C_{t}}{C_{f}^{\prime}}-0.030 \times 10^{-10} \frac{R}{C_{f}^{\prime}}
$$

Curves of $\Delta C_{t} / C_{f}^{\prime}$ and $\Delta C_{f} / C_{f}^{\prime}$ from Equation [23] are plotted in Figure 22. It may be observed that the curve of measured resistance corrected for wire drag agrees quite well at the higher Reynolds numbers with the calculated curve of $\Delta \mathrm{C}_{\mathrm{f}}^{*} / \mathrm{C}_{\mathrm{f}}^{\prime}$. This ratio is obtained by the evaluation of Equation [13] using the data from the boundary-layer surveys made with and without the trip wire.

\section{CORRECTION FOR SAND-STRIP DRAG}

Similar calculations have been made with the data obtained from the resistance tests with and without a $7 / 8$-inch wide sand strip. The sand-strip drag is assumed to be that of a trip wire, having a diameter equal to 0.00233 $\mathrm{ft}$, the mean height of the sand strip. Thus for the sand strip, the corrected curve for the increase in resistance was calculated from

$$
\frac{\Delta C_{f}}{C_{f}^{\prime}}=\frac{\Delta C_{t}}{C_{f}^{\prime}}-0.013 \times 10^{-10} \frac{R}{C_{f}^{\prime}}
$$

The curve of Equation [24] is given with that for $\frac{\Delta \mathrm{C}_{f}}{\mathrm{C}_{\mathrm{f}}^{\prime}}=\frac{\Delta \mathrm{C}_{t}}{\mathrm{C}_{\mathrm{f}}^{\prime}}$ in Figure 22 where 1 may be observed that the corrected curve from drag measurements agrees fairly well with the curve computed from the boundary-layer survey data with and without the sand strip. 

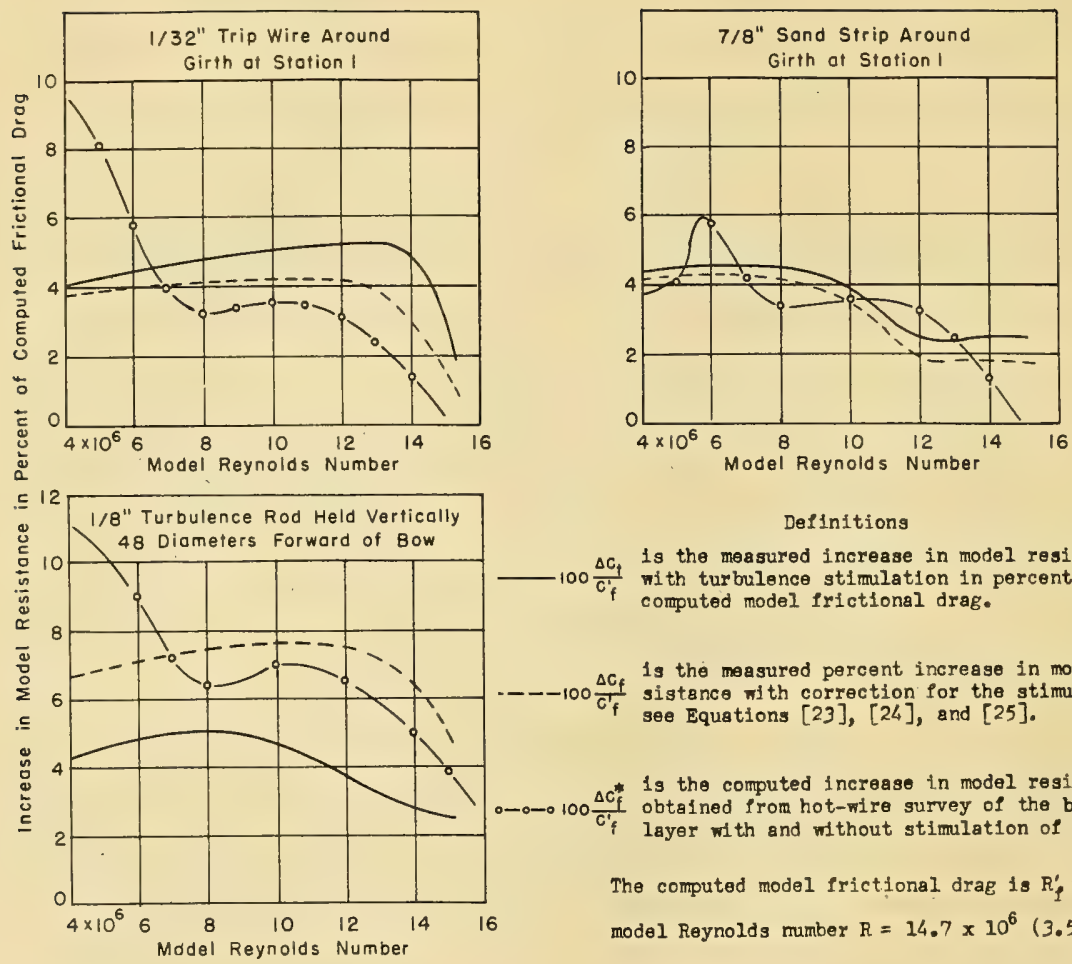

Deflnitions

$\Delta C$ is the measured increase in model resistance with turbulence stimulation in percent of the computed model frictional drag.

$\Delta C_{f}$ is the measured percent increase in model resistance with correction for the stimulator; see Equations [23], [24], and [25].

* is the computed increase in model resistance obtained from hot-wire survey of the boundary layer with and without stimulation of turbulence.

The computed model frictional drag is $\mathrm{R}_{f}^{\prime}=12$ ib at model Reynolds number $R=14.7 \times 10^{6}(3.50$ knots $)$

Figure 22 - Curves of Increase of Resistance of Tanker Model Obtained. with Various Stimulators as Derived from Drag Tests and Boundary Layer Surveys

\section{CORRECTION FOR TURBULENCE ROD}

Direct calculation of a correction for the undesirable effects of the turbulence rod on the flow about the ship model is very difflcult. The rod produces a wake or a reduction in the flow velocity in a narrow band at the bow of the model. Quite recently measurements have been made in the TMB model circulating-water channel of the wake behind a circular cylinder. At a position 48 diameters aft of a 1/8-inch rod the average value of the velocity is about $0.93 \mathrm{U}$ for a rod Reynolds number of 1900. At the bow of the ship model this wake effect is distributed over a width of about one inch. One might imagine that the wave resistance of the model is also influenced by the wave pattern set up by the rod. Some idea of the magnitude of the combined wake and wave effect of the rod on the model resistance may be obtained from 
the assumption that the total change in resistance of the model is the same regardless of the particular stimulator employed if the corrections for the extraneous effects of the stimulator are made. Making use of the results of the test with the trip wire, the corrected increase in resistance

$$
\left(\frac{\Delta C_{f}}{C_{f}^{\prime}}\right)_{r o d}=\left\{\frac{\Delta C_{t}}{C_{f}^{\prime}}+\frac{D_{W}}{R_{f}^{\prime}}\right\}_{r o d} \approx\left\{\frac{\Delta C_{f}}{C_{f}^{\prime}}+\bar{\xi}_{S}\right\}_{\text {Wire }}
$$

where $D_{W}$ is the estimated wake and wave effect of the turbulence rod, and $\bar{\xi}_{s}$ is the decrement of frictional resistance arising from the laminar flow forward of the trip wire.

The increase of model resistance $\Delta \mathrm{C}_{t} / \mathrm{C}_{\mathrm{f}}^{\prime}$ obtained from drag measurements with the rod is plotted in Figure 22 together with the corrected increase $\left(\Delta C_{f} / C_{f}^{\prime}\right)_{r o d}$ obtained from Equation [25]. At Reynolds numbers greater than $7 \times 10^{6}$ the agreement of the corrected curve with the increase $\Delta C_{f}^{*} / C_{f}^{\prime}$ derived from the results of the hot-wire survey is fair. The calculated correction to the drag data for the additional effects of the rod is seen to be from 2 to 3 percent of the calculated model frictional resistance.

In all three cases of turbulence stimulation the findings of the hot-wire survey are in good agreement with the results of the resistance tests corrected-for the undesirable effects of the stimulators.

\section{CONCLUSIONS}

A general conclusion which may be reached as a result of these experiments is that the hot-wire technique can be used in water to map qualitatively the regions of laminar, transitional, and turbulent flow in the boundary layer of any model. With such a qualitative picture a close study of the effects of various turbulence stimulators can be made and a good estimate of the increase in resistance produced by each stimulator can be accomplished. Even for this particularly large model the hot-wire investigation has shown that the extent of laminar flow would lead to a sizeable error in the prediction of the power required for the prototype. Moreover, it is now very clear that stimulation should be employed on all full-form models and should never be omitted in series tests where the effects of progressive geometrical changes are sought.

The selection of the best device for stimulating turbulence cannot be made on the basis of these limited experiments. The turbulence rod has the effect of converting the entire laminar region to turbulence at a speed lower than was possible with either the trip wire or the sand strip used in these tests. However, the resistance tests made with and without these stimulators 
on this tanker model indicate that the turbulence rod produces a somewhat smaller increase in resistance than expected from the hot-wire survey. This anomaly may possibly be attributed to the wake set up by the rod. The wire and sand strip, while not as effective at lower speeds have the advantage that their own drag tends to balance out the drag deficiency of the laminar region forward of the usual position of these stimulators.

As a result of this investigation two additional sources of turbulence stimulation were revealed. The free surface appears to give rise to additional disturbances which stimulate early transition. Hence the zone of laminar flow is reduced by this free-surface effect. Also, it was found that minute model-surface irregularities such as paint roughness are effective in producing a turbulent boundary layer. This suggests that a few isolated but judiclously positioned small roughnesses may be as effective as the other stimulators.

A valid decision on the optimum technique for stimulating turbulence must await basic measurements of the shear stresses set up in the artificially stimulated boundary layer. Such measurements may be possible with the future developments of the hot-wire system for quantitative determination of the characteristics of turbulence in water.

\section{APPENDIX}

THEORY OF THE HOT-WIRE TECHNIQUE AS APPLIED TO THE FLOW OF WATER

The basic theory of the hot wire has been given in the literature (see, e.g., References 2 and 16) but little discussion has been given to the particular aspects of the technique when the wire is used as a velocity meter in water.

The basic equation of hot-wire anemometry may be written in the following form for a wire under equilibrium conditions:

$$
\frac{1^{2} R R_{0} \alpha}{R-R_{a}}=a+b \sqrt{U \sin \beta}
$$

where $i$ is the heating current,

$\mathrm{R}$ is the mean resistance of the wire at operating temperature,

$R_{0}$ is the resistance of the unheated wire at $0^{\circ} \mathrm{C}$,

$\mathrm{R}_{\mathrm{a}}$ is the wire resistance at the temperature of the ambient fluid,

$\alpha$ is the temperature coefficient of resistance of the wire material referred to $0^{\circ} \mathrm{C}$, 
$\beta$ is the angle of flow across the wire, and

$\mathrm{a}$ and $\mathrm{b}$ are constants depending upon the wire slze, and upon the thermal conductivity, density, and specific heat of the fluid.

The constants $a$ and $b$ may be determined by calibration; that is by placing the wire in a stream the velocity of which may be varied at w11l. Equation [26] shows that the voltage drop $i R$ across the wire is a function of the square root of the fluid velocity and also that the wire should be operated in a plane perpendicular to the flow for maximum sensitivity, i.e., $\beta=\frac{\pi}{2}$

\section{CALIBRATION AND SENSITIVITY}

Quantitative applications of hot-wire techniques to water have been achieved, but only under more highly controlled conditions than those described in this report. For the qualitative survey conducted on the tanker model, wire calibrations were unnecessary and consequently, were not obtained. Also, provided sufficient sensitivity to velocity fluctuations existed for the survey, the limitations of frequency response described later in this appendix, were not remedied.

Calibration of hot-wires in water have been performed at the Taylor Model Basin and reported in Reference 17. In spite of the added complication of more rapid dirt accumulation on the wire in water than in air, consistent and repeatable calibrations can be made by brushing the wires immediately prior to each resistance measurement. The two constants $a$ and $b$ of Equation [26] can therefore be determined in a stream of variable, but known velocity. A simple calculation of the relative sensitivity of a tungsten wire (0.0003-inch diameter) in air and in water, at normal operating conditions and at the same Reynolds number has been made. The sensitivity of a hot wire placed perpendicular to the stream is defined as the rate of change of $E$ with respect to $U$ for a constant 1: Thus from [26]

$$
\left(\frac{\partial E}{\partial U}\right)_{i}=-\frac{b\left(R R_{a}\right)^{2}}{21 R_{a} R_{o} \alpha \sqrt{U}}
$$

Also, for the constant-current technique the normal operating condition in water is taken to be that current required to raise the temperature of the wire approximately $15^{\circ} \mathrm{C}$ above the temperature of the water at the mean freestream velocity of operation. In air a temperature elevation of 150 to $200 \mathrm{C}$ at mean free-stream velocity may be taken as normal. The comparison showed the hot wire to be about five times more sensitive in water than in air at the same Reynolds number because of the greater thermal conductivity and 
density of water. Since the wires used in this qualitative survey on the tanker model were not cleaned, it is reasonable to conclude that their sensitivities diminished during the experiment. In view of their relatively high initial sensitivities, however, such attenuations as might have occurred were not apparent in the response. A given wire reproduced qualitatively the same oscillogram repeatedly under the same test conditions.

\section{FREQUENCY RESPONSE}

The frequency response of the hot-wire circuit illustrated in Figure 2a depends not only on the response characteristics of the hot wire itself, but also on the characteristics of the amplifier and recording galvanometer.

The frequency response of a hot wire is dependent upon its thermal inertia or so-called thermal lag. This wire time constant is given by

$$
M=\frac{k m s\left(R-R_{a}\right)}{1^{2} R_{a} R_{0} \alpha}
$$

where $k$ is the mechanical equivalent of heat,

$m$ is the mass of the wire, and

$s$ is the specific heat of the wire.

The other symbols are as defined for Equation [26] on page 36. If the amplifier employed with the wire cannot compensate for this lag, the response to a harmonic velocity variation of constant amplitude will be such that the ratio of the amplitude of the velocity change at frequency $f$ to the amplitude at frequency zero is given by

$$
\frac{d E}{d E_{0}}=\frac{1}{\sqrt{1+4 \pi^{2} f^{2} M^{2}}}
$$

The value of $M$, in water, has been measured and found to lie in the range from 70 to $100 \mu \mathrm{sec}$. Consequently, a harmonic velocity varlation of a given amplitude would be reduced to half value at about $4000 \mathrm{cps}$ compared to 1 ts amplitude at zero frequency.

The frequency response of the TMB Type-3A amplifier used in this experiment 1 s constant from about $2 \mathrm{cps}$ to well above $10,000 \mathrm{cps}$. On the other hard, the galvanometers of the 14-channel Consolldated oscillograph attenuated signals greater than $400 \mathrm{cps}$. In view of this instrument limitation compensation of the amplifier for thermal lag similar to that described in Reference 2 was unnecessary. 
The use of a multichannel oscillograph to record a number of signals simultaneously imposed one other limitation on the frequencles recorded. It was necessary to limit the amplification to that level where legibility of a single trace was not obscured by the other traces. Hence in view of this fact, signals of high frequencles but low amplitude were not sufficiently amplified and were not discernible.

In spite of these restrictions, subsequent test records have shown velocity fluctuations in the order of $300 \mathrm{cps}$. Although it is assumed that higher frequencies were present in the turbulent boundary layers investigated, they were probably not recorded as a result of the amplification and galvanometer limitations.

\section{REFERENCES}

1. Hydrodynamics Memorandum to the Director, DTMB, entitled "Development of an Experimental Technique for Detecting Transition from Laminar to Turbulent Flow in a Boundary Layer," A11/Resistance (18:LL:fct) dated 11 August 1947.

2. Schubauer, G.B. and Klebanoff, P.S., "Theory and Application of Hot Wire Instruments in the Investigation of Turbulent Boundary Layers, "NACA ACR No. 5K27, March 1946.

3. Schubauer, G.B. and Skramstad, H.K., "Laminar Boundary Layer Oscillations and Transition on a Flat Plate," National Bureau of Standards Journal of Research, Vol. 38, February 1947.

4. Lin, C.C., "On the Stability of Two-Dimensional Parallel Flows," Quart. Applied Math, Vol. 2, No. 3, July 1945, pp 117 - 142; Vol. 3, No. 3 , October 1945, pp. 218 - 234; Vol. 3, No. 4, January 1946, pp. 277 - 301.

5. Schllchting, H., Lecture Serles "Boundary Layer Theory," Part II Turbulent Flows. NACA Tech. Memo No. 1218, Washington, D.C., April 1949, p. 33.

6. Pohlhausen, $K$, "Zur Naherungsweisen Integration der Differentialgleichung der laminaren Grenschicht," Ze1t. f. ang, Math. u. Mech., Vol. 1 (1921) No. 4, p. 252.

7. Allan, J.F. and Conn, J.F.C., "Effect of Laminar Flow on Ship Models," a paper presented at the Autumn Meeting of Institution of Naval Architects at Copenhagen, 1949. 
8. Walker, W.P., "Detection of Laminar Flow on Ship Models," Trans. of Inst. of Naval Architects, Vol. 91, 1949, pp. 220 - 236.

9. Dryden, H.L., "Air Flow in the Boundary Layer Near a Plate," NACA Report No. 562, Washington, D.C., 1936, p. 12.

10. Fage, A. and Preston, J.H., "On Transition from Laminar to Turbulent Flow in the Boundary Layer," Proc. of Royal Soc. of London, Vol. 178, August 1941, pp. $201-277$.

11. Prandt1, L. and Tietjens, O.G., "Applied Hydro- and Aeromechanics," McGraw-Hill Book Co., New York, N.Y., 1934, pp. $66-76$.

12. Gertler, M., "The Prediction of the Effective Horsepower of Ships by Methods in Use at the David Taylor Model Basin," TMB Report 576, December 1947.

13. Rossell, H.E. and Chapman, L.B., Editors of "Principles of Naval Architecture," Society of Naval Architects and Marine Engineers, New York, N.Y., 1941, Vol. II, pp. $76-89$.

14. Schlichting, H., "Experimental Investigation of the Problem of Surface Roughness," NACA Tech. Memo No. 823, Washington, D.C., April 1937, p. 26.

15. Rouse, H., "Elementary Mechanics of Flulds," Wiley and Sons, Inc., New York, N.Y., 1946, page 247.

16. Willis, J.B., "Review of Hot Wire Anemometry," Report ACA-19, Australian Council for Aeronautics, October 1945.

17. Macovsky, M.S., "The Measurement of Turbulence in Water," TMB Report. 670 , october 1948. 

